Tecnología e Innovación

Tecnologia e Inovação

Tecnology and Innovation
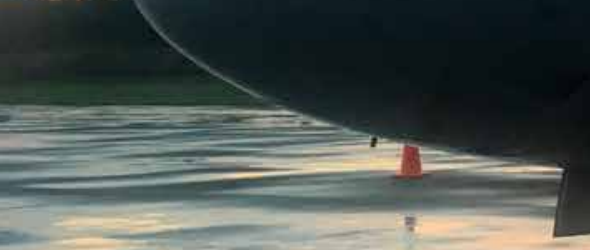

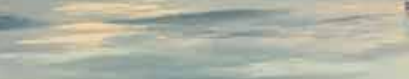
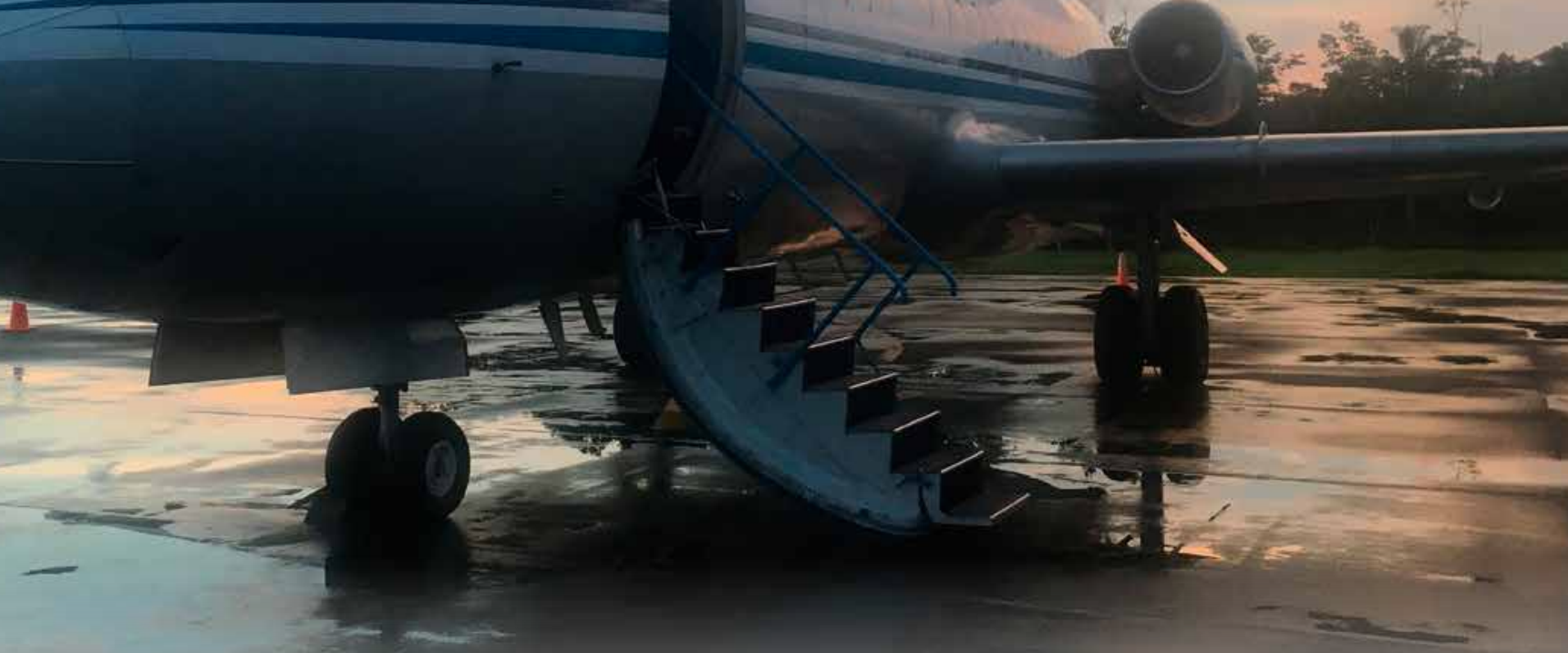

\title{
REVISIÓN DE SISTEMAS DE CONTROL EN RED COMO BASE PARA SISTEMAS SATELITALES DE PEQUEÑA ESCALA ${ }^{1}$
}

REVIEW OF NETWORK CONTROL SYSTEMS AS A BASIS FOR SMALL-SCALE SATELLITE SYSTEMS ${ }^{2}$

REVISÃO DE SISTEMAS DE CONTROLE DE REDE COMO BASE PARA SISTEMAS DE SATÉLITE DE PEQUENA ESCALA

Germán Wedge Rodríguez Pirateque ${ }^{4}$

Jorge Sofrony Esmeral ${ }^{5}$

Centro Tecnológico de Innovación Aeronáutica, CETIA - JEA y Universidad Nacional de Colombia. Bogotá, Colombia

\section{CIENCIA Y PODER AÉREO}

ISSN 1909-7050 / E- ISSN 2389-9468 / Volumen 13 / Número 2 / julio-diciembre de 2018/ Colombia /pp. 90-125 Recibido: 06/03/2018

Aprobado par evaluador: 26/08/2018

Doi: 10.18667/cienciaypoderaereo.604 
Para citar este artículo:

Rodríguez, G. W. y Sofrony, J. (2018). Revisión de sistemas de control en red como base para sistemas satelitales de pequeña escala. Ciencia y Poder Aéreo, 13(2), 90-125. doi: 10.18667/cienciaypoderaereo.604

'Artículo de revisión asociado al proyecto "Defensa de la soberanía: sistemas de satélites de pequeña escala para servicios aeroespaciales de monitoreo y vigilancia del territorio nacional".

${ }^{2}$ Review article associated with the project "Defense of sovereignty: small-scale satellite systems for aerospace services for monitoring and surveillance of the national territory".

${ }^{3}$ Artigo de revisão associado ao projeto "Defesa da soberania: sistemas de satélite de pequena escala para serviços aeroespaciais para monitoramento e vigilância do território nacional."

${ }^{4}$ MsEng. Estudiante doctorado en Ingeniería Mecánica y Mecatrónica de la Universidad Nacional de Colombia. ORCID: https://orcid.org/0000-0002-86170558.

Correo electrónico: gwrodriguezp@unal.edu.co; german.rodriguez@fac.mil.co

${ }^{5} \mathrm{PhD}$. Profesor titular asociado al Departamento de Ingeniería Mecánica y Mecatrónica de la Universidad Nacional de Colombia.

Correo electrónico: jsofronye@unal.edu.co
Resumen: el presente artículo parte de la premisa complementaria entre sistemas satelitales de gran escala y sistemas en red de pequeña escala que puedan suplir los mismos servicios, por lo tanto, se presentan diferentes enfoques de trabajos desarrollados en torno a los aportes de sistemas de control en red, como fundamento al desarrollo de nuevas tecnologías en la operación de sistemas satelitales y de servicios aeroespaciales, los cuales se han convertido en un desafío permanente para diferentes disciplinas y países en vía de desarrollo alrededor del mundo. En este sentido, se realizó una revisión descriptiva organizada mediante tópicos y descriptores para la búsqueda de factores de diseño en relación con los sistemas de operación y control que han sido fuente de trabajo, tanto para la configuración de constelaciones como de clúster satelitales; logrando con esto identificar las tendencias y aportes que en materia de sistemas multiagente se han desarrollado, así como las pautas necesarias para la formulación de soluciones a las necesidades de coordinación de sistemas de bajo costo, que sean capaces de brindar alternativas sostenibles para países como Colombia frente a la democratización del espacio. Con esta revisión se obtienen como resultados diferentes lineamientos para la definición de requerimientos, la descripción de arquitecturas y modelos de referencia, así como algunos factores de uso en tecnologías comparadas, que en términos prácticos brindan las herramientas para la generación de alternativas de diseño de misión en aplicaciones de seguridad crítica y defensa, que pueden ser extendidas en enfoques de sistemas satelitales multiagente.

Palabras clave: sistemas multiagente, arquitecturas satelitales, constelaciones, control en red.

Abstract: This article starts from the complementary premise between large-scale satellite systems and small-scale network systems that can supply the same services. Therefore, different approaches to work developed around the contributions of network control systems are presented, as a basis for the development of new technologies in the operation of satellite systems and aerospace services, which have become a permanent challenge for different disciplines and developing countries around the world. In this sense, a descriptive review was organized by topics and descriptors for the search of design factors in relation to the operation and control systems that have been a source of work, both for the configuration of constellations and satellite clusters; achieving with this to identify the trends and contributions that have been developed in the field of multi-agent systems, as well as the necessary guidelines for the formulation of solutions to the coordination needs of low-cost systems, which are capable of providing sustainable alternatives for countries such as Colombia in the face of the democratization of space. With this review, different guidelines for the definition of requirements, the description of architectures and reference models are obtained, as well as some factors of use in comparative technologies, which in practical terms provide the tools for the generation of mission design alternatives. in critical security and defense applications, which can be extended in multi-agent satellite systems approaches.

Keywords: multi-agent systems, satellite architectures, constellations, network control.

Resumo: Este artigo é baseado na premissa de complementaridade entre os sistemas de satélite, sistemas de rede em grande escala pequena escala que podem fornecer os mesmos serviços, portanto, diferentes abordagens trabalho desenvolvido em torno da rede sistema de controle de entrada são apresentados, como base para o desenvolvimento de novas tecnologias na operação de sistemas de satélite e serviços aeroespaciais, que se tornaram um desafio permanente para diferentes disciplinas e países em desenvolvimento em todo o mundo. A este respeito, uma revisão descritiva organizado por tópicos e palavras-chave para fatores de design da pesquisa relacionados com os sistemas de comando e controlo que têm sido uma fonte de trabalho, tanto para a configuração de grupo de constelações de satélites foi feita; assim, conseguir identificar tendências e contribuições no campo de sistemas multi-agente, foram desenvolvidos e orientações necessárias para formular soluções para as necessidades de coordenação dos sistemas de baixo custo que são capazes de fornecer alternativas sustentáveis para países como a Colômbia contra a democratização do espaço. Com esta revisão são obtidos como resultado diretrizes diferentes para definição de requisitos, descrição de arquiteturas e modelos de referência, bem como alguns fatores utilizar tecnologias comparados, em termos práticos, fornecer ferramentas para a geração de missão alternativas de projeto em aplicações críticas de segurança e defesa, que podem ser estendidas em abordagens de sistemas de satélites multiagentes.

Palavras-chave: sistemas multiagentes, arquiteturas satelitais, constelações, controle de redes. 


\section{Introducción}

El artículo tiene como objeto la búsqueda de referentes para el diseño de soluciones de bajo costo como alternativa sustitutiva al uso de satélites monolíticos o de gran escala en la prestación de servicios aeroespaciales, de donde surge la necesidad de caracterizar configuraciones y métodos de operación de sistemas de control en red, que sirvan como fundamento para la identificación de soluciones en el uso de satélites de pequeña escala con capacidad de compartir recursos en aplicaciones específicas.

Para el caso particular, se toman como referencia los caminos recorridos e iniciativas que han abordado tanto universidades como entidades públicas o privadas, frente al reto espacial colombiano, así como los avances que en diferentes disciplinas como la robótica, posibilitan el uso de estrategias que puedan tomarse como referentes para los sistemas de control en red satelitales.

Casos particulares son las constelaciones de sistemas de posicionamiento global (GPS) o Iridium, las cuales se pueden considerar como un conjunto o grupo cooperativo de agentes interconectados en red, con características idénticas y en operación centralizada, o como el caso de los clúster, por ejemplo el sistema F6 de la Agencia de Proyectos de Investigación Avanzada de Defensa (DARPA), configurados con equipos heterogéneos en operaciones descentralizadas, con posibles configuraciones de formación en vuelo o enjambres según sea la necesidad de compartir recursos para operaciones tipo (Alvarez \& Walls, 2016), como se ilustra en la figura 1, donde se presentan configuraciones básicas de nanosatélites dispuestos para la generación de protocolos de un sistema de control en red tipo clúster.

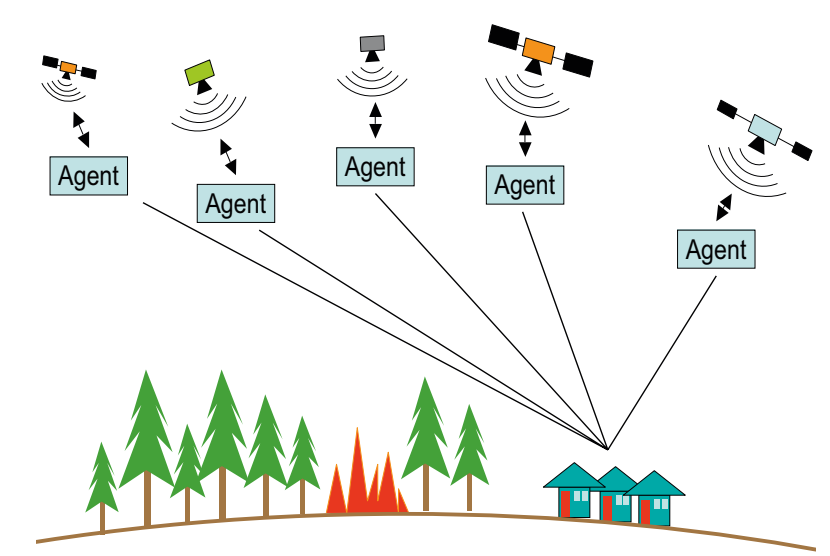

Figura. 1. Pequeña comunidad de nanosatélites Fuente. Holmes et al, 2012.
En este sentido, el artículo aborda los sistemas en red desde un contexto general dispuesto en la segunda sección, donde se presentan los diferentes requerimientos, servicios y gestores aeroespaciales como base descriptiva de las primeras etapas de un diseño de misión, posteriormente en la sección tres se presentan las diferentes arquitecturas satelitales dentro de las cuales se puedan configurar las necesidades del servicio aeroespacial requerido, en la sección cuatro y cinco se refieren diferentes enfoques de modelos de sistemas en red, para observar las disposiciones y técnicas de configuración de agentes, que finalmente en las secciones seis y siete, se concretan en aplicaciones y tecnologías comparadas para la configuración de sistemas en red que pueden ser aplicados en sistemas satelitales multiagente.

El método de estructuración y análisis de la información se basa en una revisión descriptiva donde se definen tópicos, descriptores y se extraen los principales factores de diseño a ser tenidos en cuenta para la formulación del problema de configuración de los agentes en red que suplan los servicios de satélites de gran escala, como se muestra en la tabla 1, donde se enfatizan los factores de análisis útiles para la estructuración de parámetros y requerimientos de misión de proyectos específicos.

Tabla 1

Estructuración de la revisión descriptiva

\begin{tabular}{|c|c|c|c|}
\hline Sección & Tópico & Descriptores & $\begin{array}{l}\text { Factor de } \\
\text { análisis }\end{array}$ \\
\hline \multirow[b]{2}{*}{$\|$} & $\begin{array}{l}\text { Requerimientos } \\
\text { del sistema en } \\
\text { red }\end{array}$ & $\begin{array}{l}\text { - Generales } \\
\text { - Logísticos } \\
\text { - Operacionales }\end{array}$ & $\begin{array}{l}\text { Diseño de } \\
\text { misión y } \\
\text { carga útil }\end{array}$ \\
\hline & $\begin{array}{l}\text { Servicios } \\
\text { y gestores } \\
\text { aeroespaciales }\end{array}$ & $\begin{array}{l}\text { - Segmentos } \\
\text { de uso } \\
\text { - Prospectiva } \\
\text { tecnológica }\end{array}$ & $\begin{array}{l}\text { Operación del } \\
\text { sistema }\end{array}$ \\
\hline III & Arquitecturas & $\begin{array}{l}\text { - Sistemas } \\
\text { - Subsistemas }\end{array}$ & $\begin{array}{l}\text { Configuración } \\
\text { del sistema }\end{array}$ \\
\hline IV-V & $\begin{array}{l}\text { Modelos de } \\
\text { referencia - } \\
\text { sistemas en red }\end{array}$ & $\begin{array}{l}\text { - Diseños de } \\
\text { misión } \\
\text { - Formaciones }\end{array}$ & $\begin{array}{l}\text { Control del } \\
\text { sistema }\end{array}$ \\
\hline $\mathrm{VI}$ & Seguridad crítica & $\begin{array}{l}\text { - Diseño orbital } \\
\text { - Sistemas de } \\
\text { prueba }\end{array}$ & $\begin{array}{l}\text { Pruebas del } \\
\text { sistema }\end{array}$ \\
\hline VII & $\begin{array}{l}\text { Tecnologías } \\
\text { comparadas }\end{array}$ & $\begin{array}{l}\text { - Robótica } \\
\text { móvil }\end{array}$ & $\begin{array}{l}\text { Emulación de } \\
\text { sistemas }\end{array}$ \\
\hline
\end{tabular}

Fuente: elaboración propia. 


\section{Contexto general}

\section{Requerimientos generales}

El reto espacial colombiano demanda no solo la definición de necesidades en servicios aeroespaciales, sino también la búsqueda de arquitecturas, modelos estimados, perspectivas de uso, logística, operación e incluso tendencias tecnológicas, para el uso de pequeños satélites frente a los clásicos satélites monolíticos (Abbott, 2000). Como es el caso de la estimación de modelos matemáticos alternativos para las configuraciones de constelaciones, ya sea con topologías clásicas de sistemas y modelos de grafos, o modelos de cooperación, sistemas multiagente, incluso el uso de la fusión sensorica y el análisis de sistemas dinámicos distribuidos con configuraciones de agentes como líder seguidor, entre otros.

\section{Requerimientos logísticos}

La disposición de los servicios aeroespaciales mediante el uso de constelaciones o clúster de pequeños satélites (Álvarezy Walls, 2016), demanda múltiples especificaciones, como el diseño de misión, los sistemas de control en tierra, la administración de los enlaces de comunicaciones, el control de la plataforma satelital, los recursos para la descarga y procesamiento de datos, el personal operativo y de soporte técnico para los movimientos, entre muchos otros requerimientos, según sea el diseño de misión establecido (Engelen, 2016).
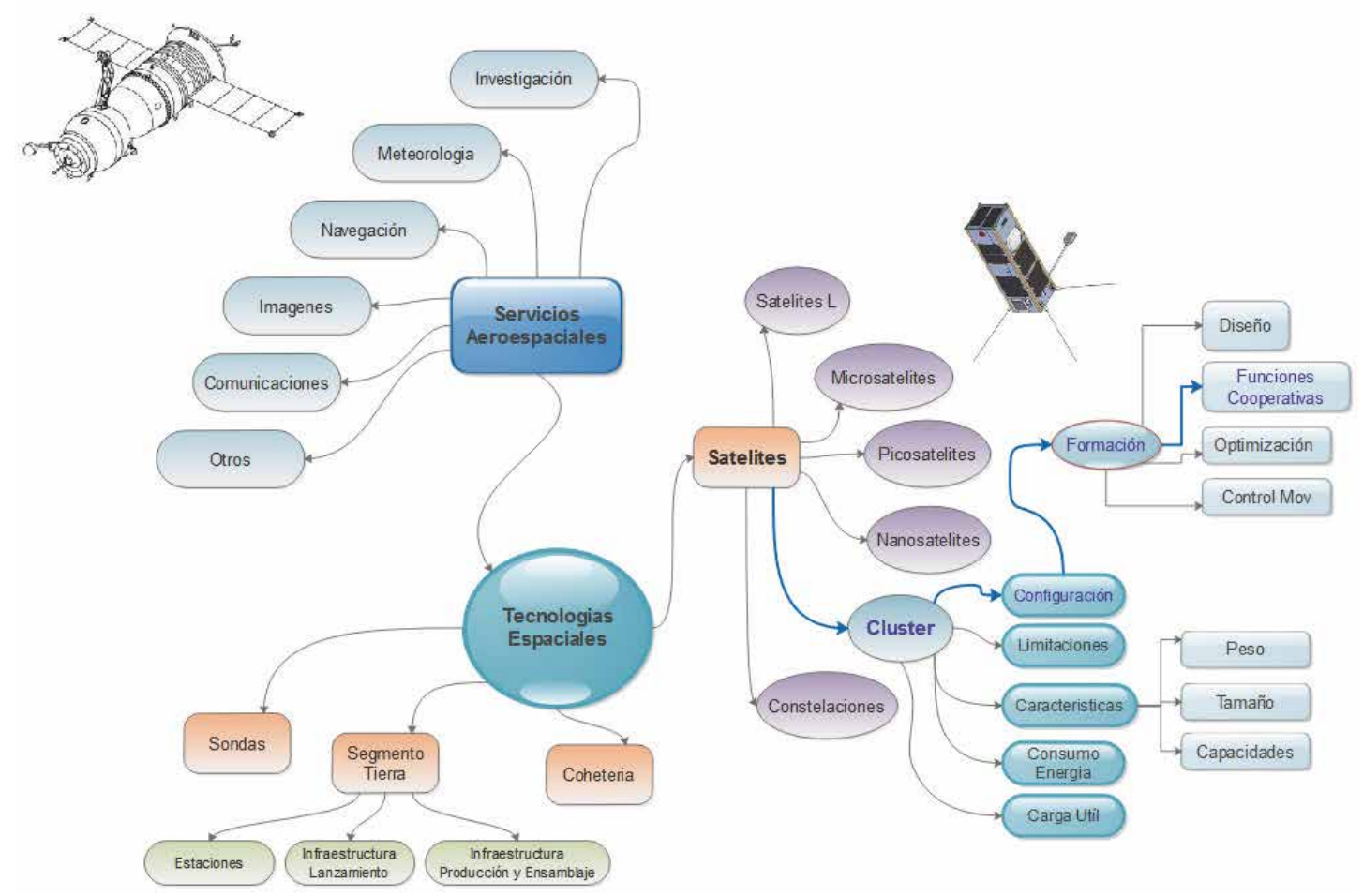

\section{Requerimientos operacionales}

El funcionamiento básico de los equipos en red requiere la operación y disponibilidad de recursos en línea $24^{*} 7$, con estaciones de trabajo en tierra, tanto para la descarga de datos como para el procesamiento y postprocesamiento, hardware, software, control y ajuste de los sensores a bordo, sistemas de potencia, navegación, propulsión y sistemas de control y determinación de actitud de cada satélite que en adelante se identificarán como los agentes o nodos específicos de las topologías de red y cooperación de recursos de ser necesario (Álvarez y Walls, 2016).

\section{Servicios aeroespaciales}

Los servicios aeroespaciales cubren una amplia gama de necesidades de operación y aprovechamiento de los sistemas satelitales que se puedan estructurar para su implementación (Schilling, 2017), tales como el monitoreo rural o urbano, navegación, inteligencia, meteorología y predicción, vigilancia, adquisición de imágenes, reparación de satélites, observación, teledetección, exploración espacial, comunicaciones, fines científicos, productividad de cultivos, e incluso recolección de basuras espaciales y análisis de los ciclos del agua, la energía y el carbono, entre otros.

La figura 2, ilustra los diferentes segmentos de uso junto con algunas de las alternativas de satélites de pequeña escala, con tecnologías complementarias para su

Figura 2. Segmentos de uso

Fuente: elaboración propia. 
puesta en órbita y operación, además de los descriptores requeridos para la configuración de los agentes en red (Poghosyan y Golkar, 2016).

En este sentido, el contexto general presenta no solo las necesidades a través de los servicios aeroespaciales requeridos, sino también algunas estrategias para su implementación e incluso algunos factores que evidencian la necesidad de uso de los sistemas satelitales en territorios de vulnerabilidad, como el caso de incidencia del conflicto armado, la deforestación, el monitoreo y vigilancia de infraestructura de gran escala y la actualización y formación catastral multipropósito, como mecanismos de referenciación para el uso apropiado de las tecnologías satelitales (Bouwmeester y Guo, 2010).

En referencia al caso colombiano y abordando las necesidades identificadas de los servicios aeroespaciales, se tienen casos como los sistemas de acceso a teleeducación, telesalud, telemedicina en regiones rurales remotas con infraestructura limitada.

Donde se proyectaría un posible sistema espacial de observación de la tierra para su uso en agricultura de precisión, seguridad alimentaria, manejo sostenible de bosques y recursos hídricos, cambio climático, mitigación y manejo de desastres naturales, que entre otros, son los enfoques y necesidades de aprovechamiento del sistema en red, que han sido propuestos por la Dirección de Colciencias, en el marco de la "Ciencia y tecnología espacial para la paz y el desarrollo sostenible del país".

En esta perspectiva, el sistema de control en red requeriría como mínimo la operación de 8 satélites, capaces de proveer un servicio de contenidos educativos de calidad, a través de un centro de operaciones y contenidos (COC), donde se presten los servicios enlazados con nodos educativos dependientes (NED) e independientes (NEI-PequeñaRural) en zonas de alta vulnerabilidad socioeconómica, para finalmente proveer dichos servicios a las escuelas y aulas, con contenidos, actividades y operaciones de clase mundial.

Estas necesidades están siendo cubiertas con ejemplos como el satélite de educación EDUSAT en la India, lanzado en 2004, con transmisiones de televisión en aproximadamente 31.000 aulas unidireccionales, TV interactiva, videoconferencia y conferencias e instrucción basada en web, con 4.000 aulas interactivas y transmisiones bidireccionales. Otras soluciones como la universidad virtual africana, con 15 estados miembros, 50 instituciones asociadas y 27 países africanos, a través del programa basado en satélite de educación a distancia y e-learning.

Adicional al caso africano, el operador satelital Intelsat en asocio con Mindset Network, intensificaron las operaciones satelitales en Sudáfrica, proporcionando acceso a un ancho de banda gratuito para contenido educativo en las áreas de mayor interés de la zona como VIH/SIDA, tuberculosis, ciencia, matemáticas, informática e inglés, tanto a profesores como estudiantes y trabajadores de la salud.

Por su parte, Brasil ha desarrollado activamente su programa de educación universitaria satelital desde el año 2003, proporcionando intercambio científico en educación, e-learning e información para búsqueda de oportunidades de formación, pasando de 950.000 usuarios desde el 2010 a 3.1 millones proyectados para el 2018.

Entre otros casos de éxito de la aplicación de estas tecnologías para necesidades de desarrollo sostenible, se tienen, la telemedicina en Mongolia, la teleconsulta especializada en Magdalene Islands, cuidado dermatológico en Bangladesh mediante transmisiones telemétricas, telepatología virtual en Egipto, telesiquiatría rural en Wagga Wagga, y telemedicina en Noruega, lo anterior teniendo en cuenta el esquema general de transmisión de datos, ilustrado en la figura 3, con sus respectivos equipos de soporte, tanto para recepción como para envío de información.

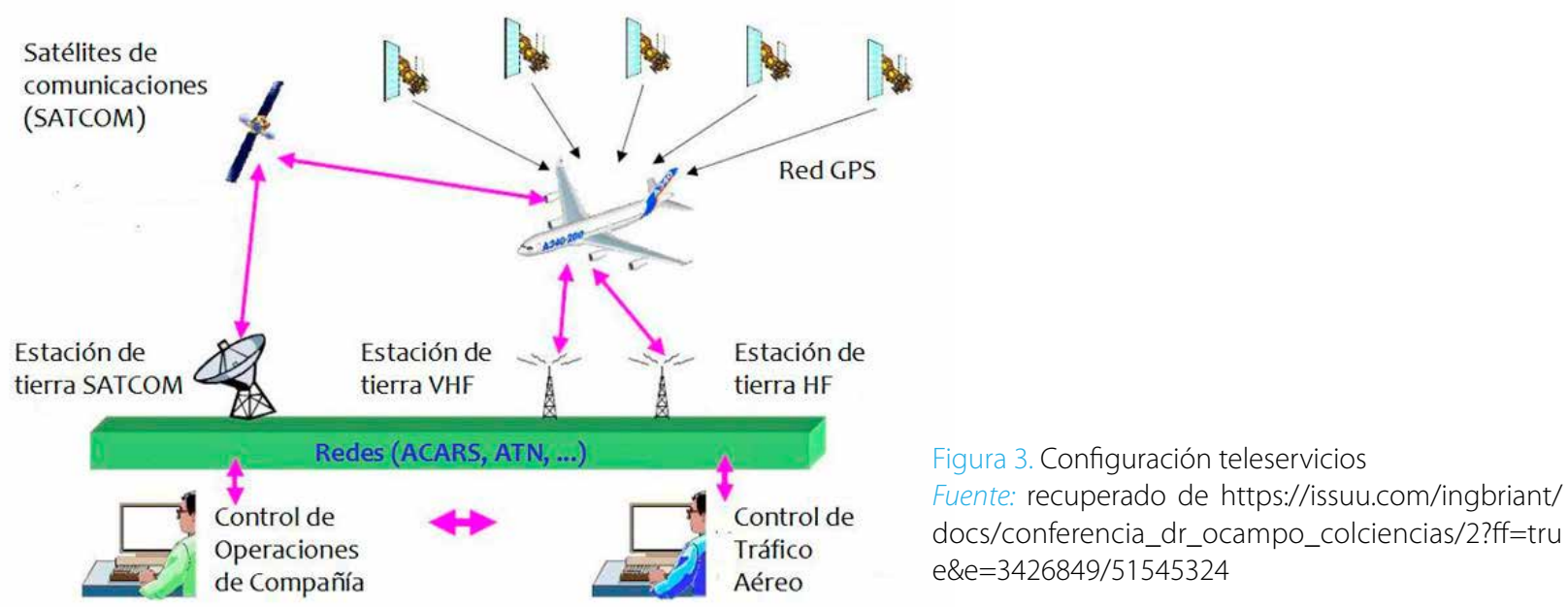

94 | Revisión de sistemas de control en red como base para sistemas satelitales de pequeña escala 
Por su parte, el concepto de seguridad y defensa articulados con la fuerza pública y empresas con amplia experiencia en soluciones satelitales, plantean otras alternativas que pueden integrar las necesidades de país formuladas previamente.

En este sentido, se plantea una alternativa de uso representada en la disposición de una constelación multimisión, con unidades de referencia, como se ilustra en la figura 4, con capacidad de 20 nanosatélites de configuración 6U, 14 para comunicaciones multibanda y tracking, 4 para imágenes $5 \mathrm{~m} /$ pixel con modelo de síntesis de color y región espectral del infrarrojo cercano $\mathrm{RGB}+\mathrm{NIR}$ y 2 nanosatélites para imágenes de $1 \mathrm{~m}$ /pixel RGB+NIR, con cobertura continua, centro de integración y lanzamiento.

Con este propósito se buscaría una proyección en transferencia de tecnologías, tanto en gestión del progra- ma como en diseño de misión, registro satelital, licencia de frecuencias, contratación del lanzador, ingeniería de sistemas, fabricación de componentes, integración, pruebas y campaña de lanzamiento, puesta a punto y operación de los equipos como es el caso de la coordinación de capacidades distribuidas en red respecto al protocolo general de integración de los segmentos de usuario, tierra y espacio.

En esta disposición se consideran todos y cada uno de los elementos requeridos para la operación y enlace general de datos del sistema.

\subsection{Gestores de servicios aeroespaciales}

El desarrollo satelital mundial ha tenido múltiples actores, dentro de los cuales figuran no solo los países líderes (figura 5) respecto al nivel de patentes y actividad inventiva en sistemas de satélites de pequeña escala, sino también los países en vía de desarrollo e incluso las alianzas que

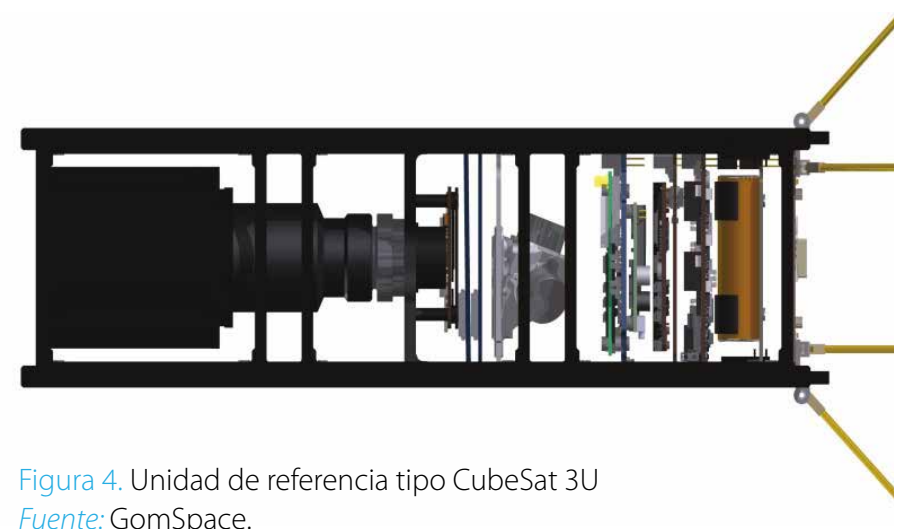

Fuente: Gomspace.

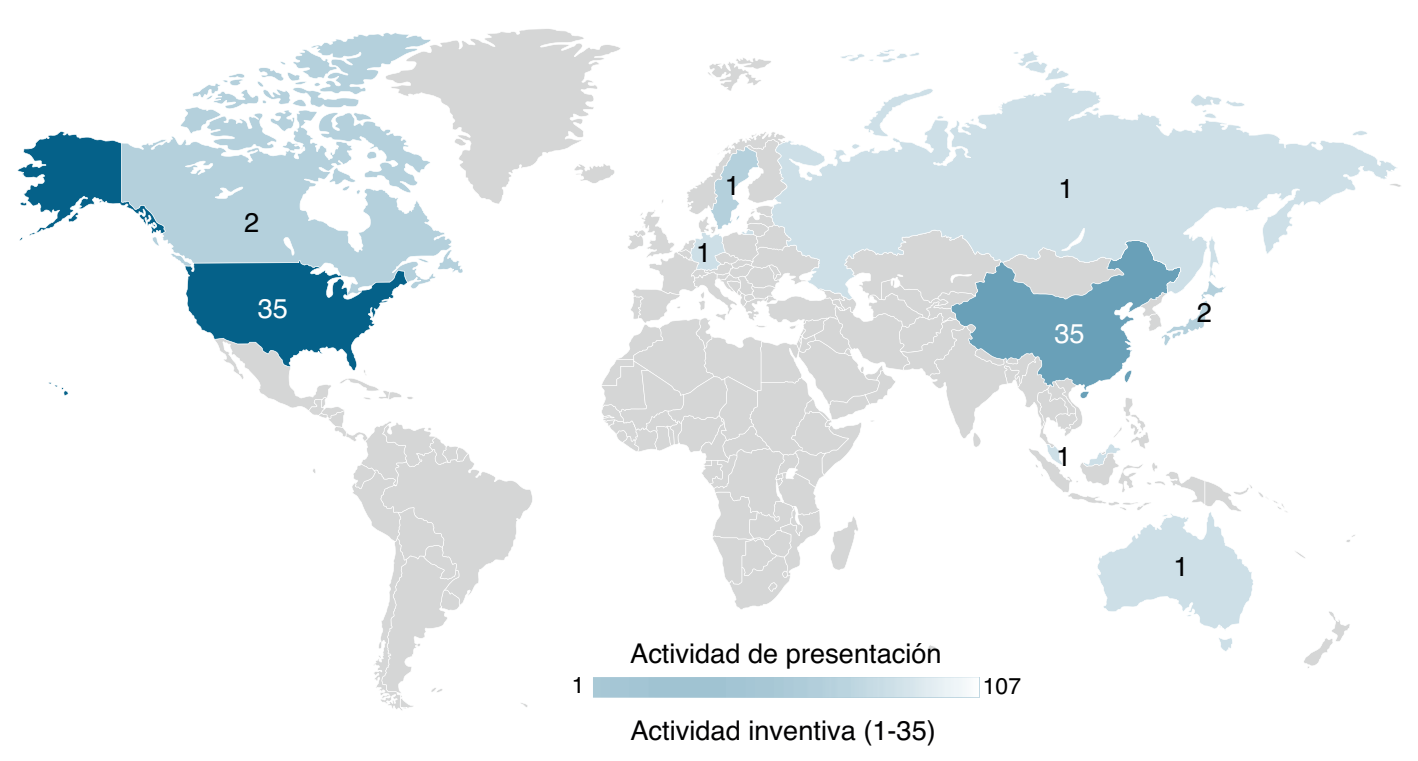

Figura 5. Países líderes según la actividad inventiva y de patentes

Fuente: (Medina, 2017) Thomson Innovation, Espacenet, USPTO, Latipat, entre otras. 
estos han generado para proyectar el concepto espacial tanto en la estrategia como en las capacidades operativas de los diferentes protagonistas.

De igual modo, se han consolidado las capacidades en diferentes agencias y a través de múltiples operadores o empresas gestores del sector aeroespacial como por ejemplo Boeing, Airbus, Space X, Gomspace, Kickstarter, Karten Space, Skycube, NanoRacks, Satellogic, PlanetLab, Wanweb, Terran Orbital, Ideatech, Secoia en la cuota colombiana, entre muchas otras a nivel mundial.

De igual manera en la figura 6, se presentan las diferentes entidades líderes en la generación e impacto de soluciones espaciales.

Con estos referentes de producción inventiva la generación de las cadenas de valor en el sector aeroespacial, han traído a colación la necesidad de evolucionar en todo el concepto de operaciones y logística frente a la demanda de servicios. Con lo cual una de las tantas opciones que ha sido trazada, es la proyección de capacidades desde los pequeños sistemas satelitales, que de alguna manera posibiliten la búsqueda de servicios particularizados a sus clientes y que suplan la integración de nuevas tecnologías a la vanguardia del sector.

En el crecimiento y demanda del servicio radica el término de "democratización del espacio", el cual está abriendo las puertas a múltiples posibilidades, con las que se están beneficiando nuevos actores dentro del escenario espacial, incluso la gestión industrial (figura 7), en la representación de productos y servicios requeridos para satélites de pequeña escala; logrando así, vincular diferentes contextos de operación como fabricantes de componentes, diseñadores de misión, gestores tecnológicos, entre otros recursos para la extensión del medio espacial tanto en su aprovechamiento como en su posicionamiento y gestión.

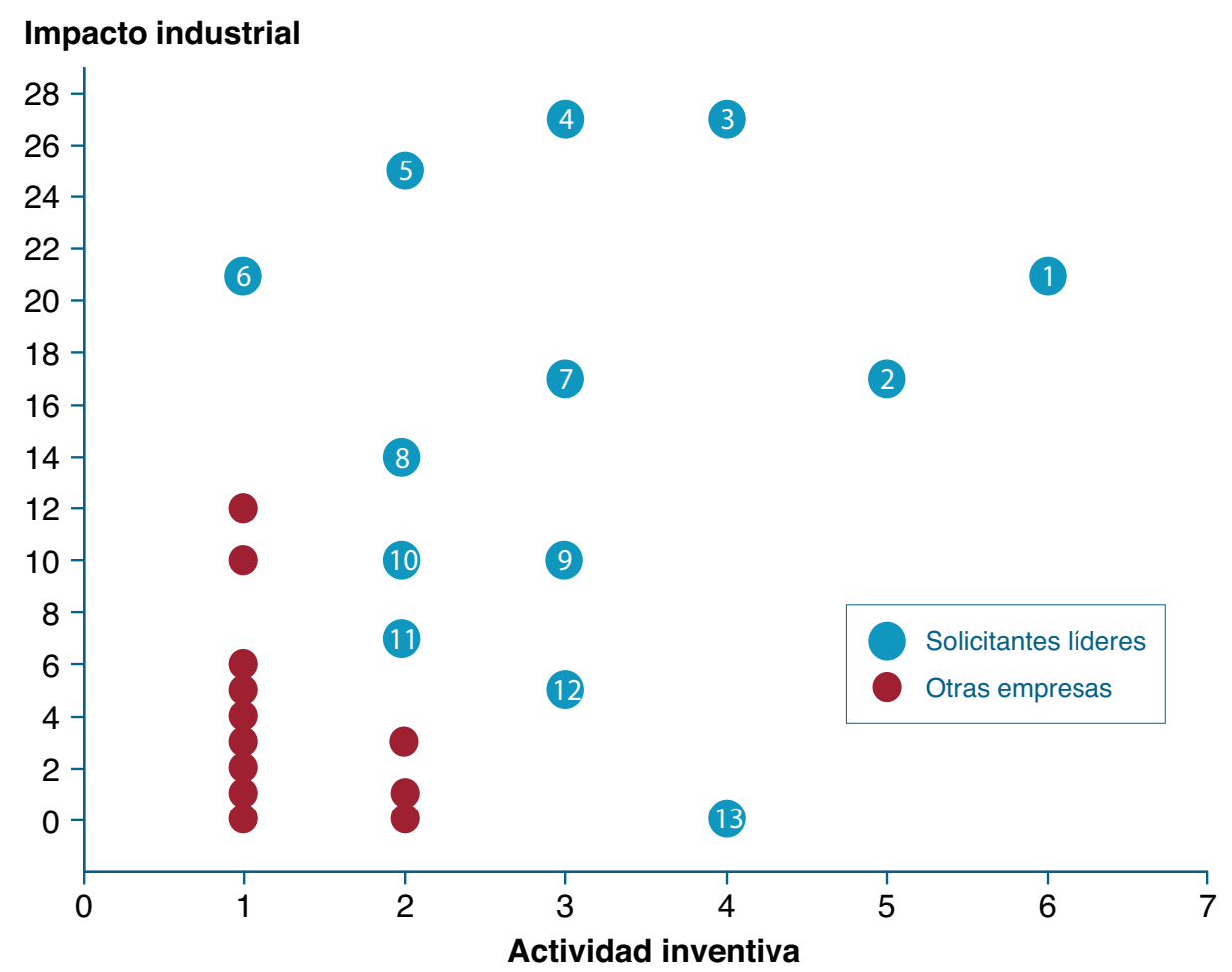

\author{
7 Northwestern Polytechnical University (CN) \\ 8 Univ Beihang (CN) \\ 9 Jiangnan University $(\mathrm{CN})$ \\ 10 Zhejiang University (CN) \\ 11 Boeng Co. (US) \\ 12 U.S.A. National Aeronautics \\ 13 Spire Global Inc. (US)
}

Figura 6. Solicitantes líderes identificados a partir de la relación entre actividad inventiva e impacto industrial

Fuente: Medina, 2017, Thomson Innovation, Espacenet, USPTO, Latipat, entre otras. 


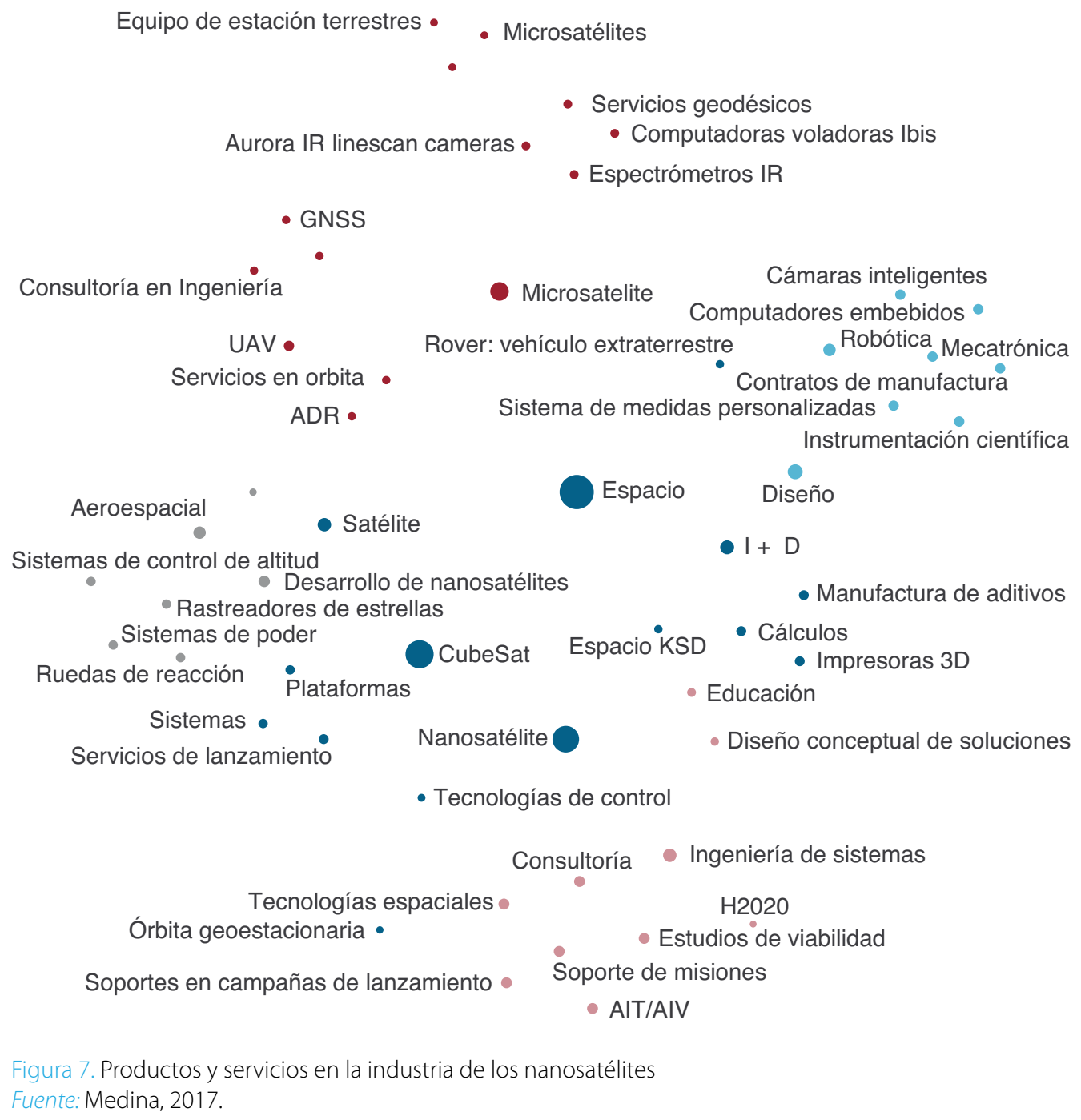

Otras de las líneas de acción dentro del contexto de democratización del espacio se centran en el incremento de los lanzamientos, el uso de sistemas satelitales de pequeña escala y el incremento de las publicaciones y proyecciones de acuerdo a lo ilustrado en la figura 8.

En este sentido, es importante identificar diferentes tipos de tecnologías o artefactos aeroespaciales con los cuales se están supliendo los servicios en órbita, tipos de redes multiagente configuradas con dichos equipos, tipos de enlaces y bandas de operación de datos óptimos, formas de configuración en hardware y software, entre otros aspectos con las que se han respaldado los mencionados servicios en tiempo real, características de controladores,

modelos de control aplicados para el uso de recursos compartidos y finalmente las últimas tecnologías que aporten valor a las redes multiagente.

Si bien el desarrollo satelital y sus servicios asociados han tenido su mayor esplendor desde el siglo pasado, vale la pena destacar que hay una naciente industria dedicada a los propósitos de operar equipos con características físicas de reducido tamaño, de bajo impacto ambiental y lógicamente de alto rendimiento, como lo muestra la figura 9, respecto a la posibilidad de desarrollar líneas de producción o demás sistemas útiles para la gestión de servicios aeroespaciales en diferentes latitudes. 


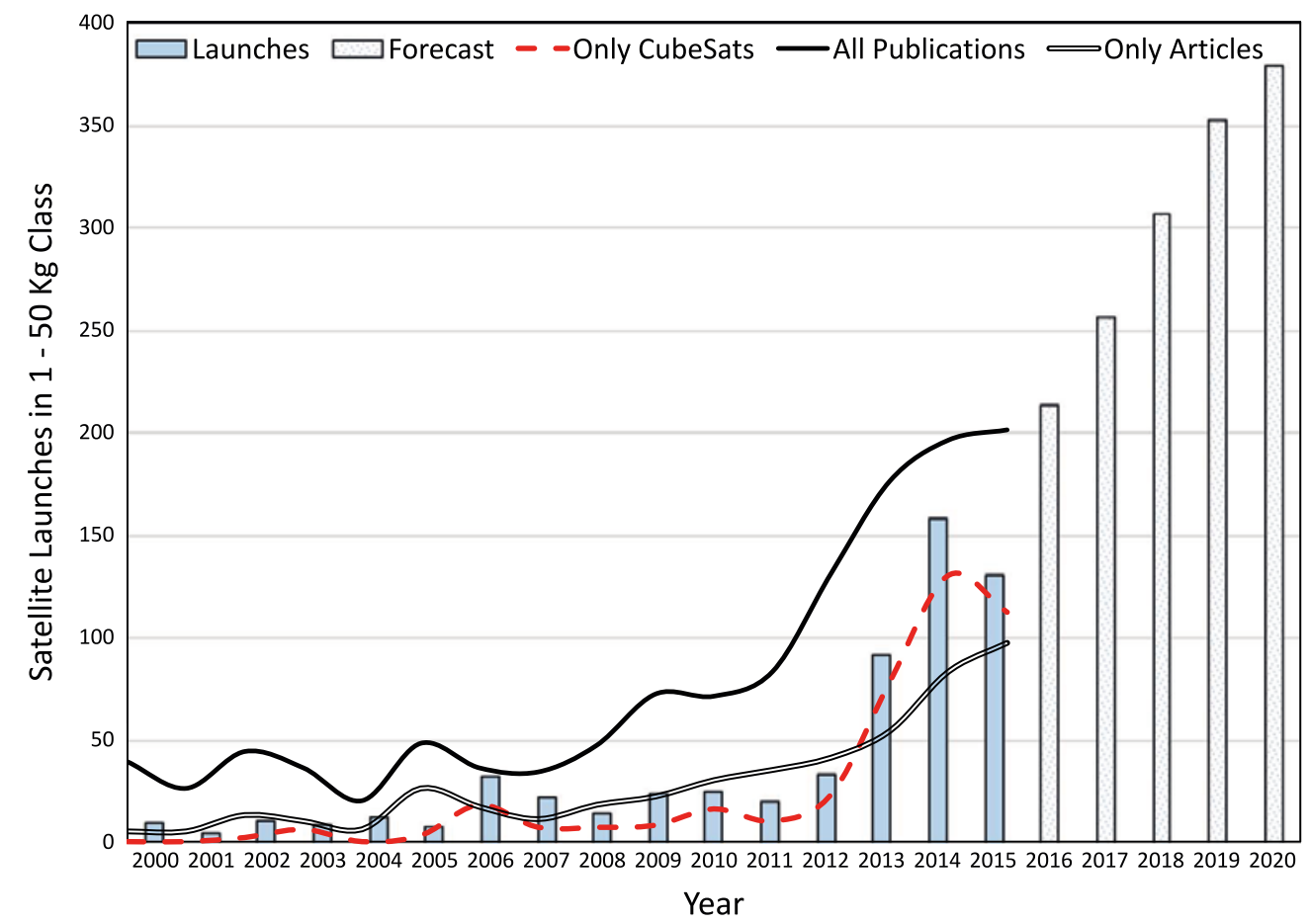

Figura 8. Descripción retro y prospectiva de las tecnologías espaciales Fuente: Poghosyan y Golkar, 2016.

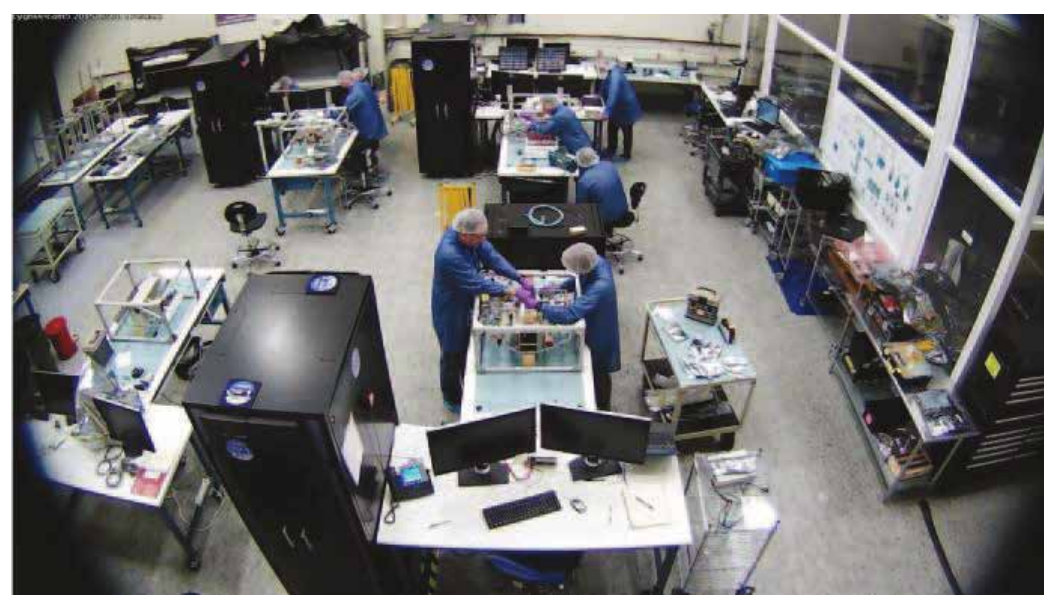

Figura 9. Línea de producción de microsatélites Fuente: Álvarez y Walls, 2016. 


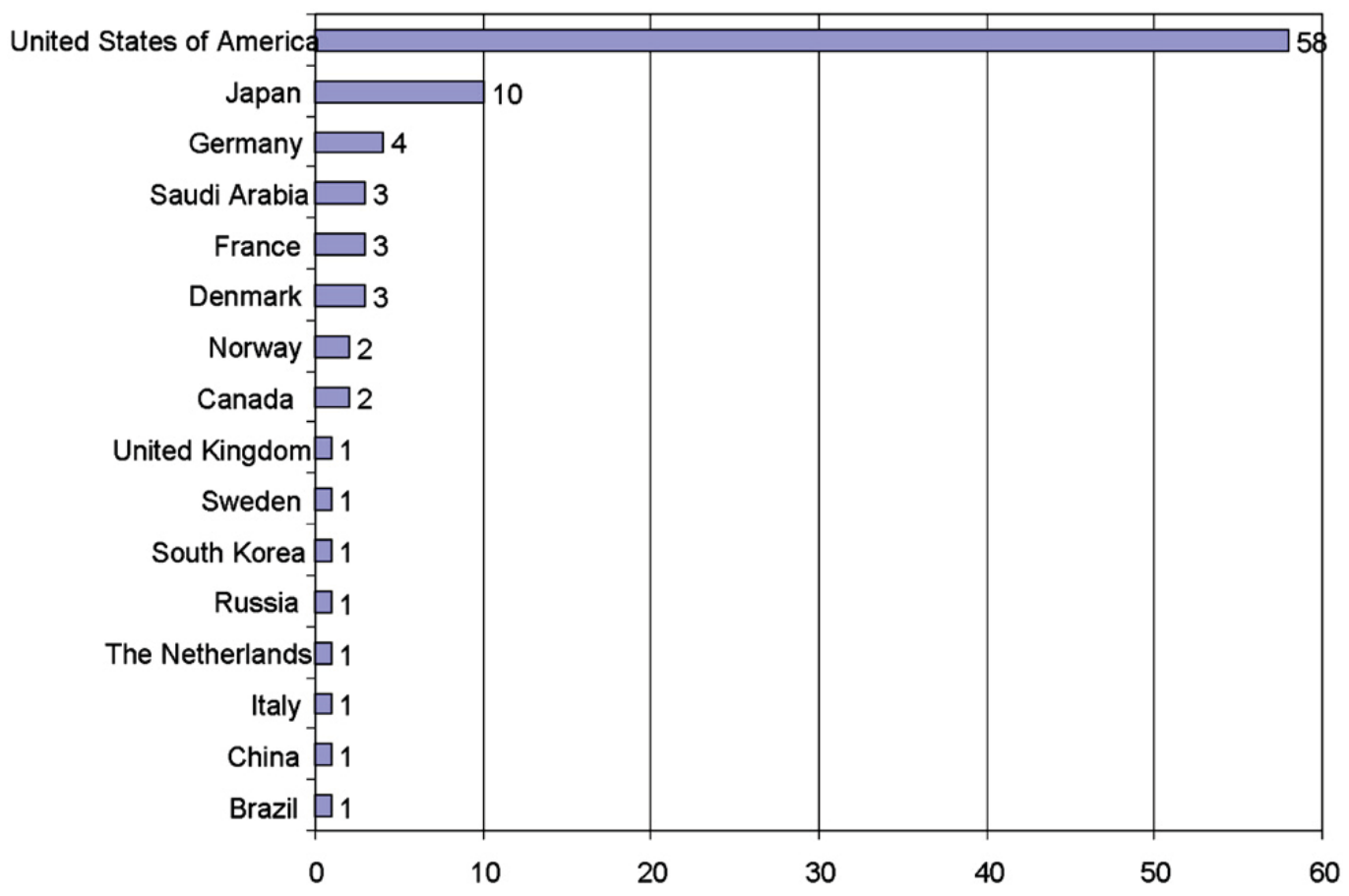

Figura 10. Distribución geográfica de desarrolladores de pico y nanosatélites

Fuente: Bouwmeester y Guo, 2010.

En términos de los últimos desarrollos y tendencias que desde el punto de vista comercial están cobrando amplia significancia y participación de diferentes agencias, se encuentran los CubeSat como parte de las herramientas útiles para la configuración de sistemas en red con satélites de escala reducida (figura 10), respecto a la distribución geográfica de desarrolladores más significativa de proveedores de servicios, donde Estados Unidos lidera mayoritariamente en la participación de mercado.

Estos satélites fueron el resultado de un proyecto materializado con el nombre de CubeSat por parte de la Universidad Politécnica de California (Cal Poly) y desde 1999 con la Universidad de Stanford. Con el propósito de estandarizar los satélites de pequeña escala y aportar en el ahorro de costos y tiempos de desarrollo, quedando formalizado el estándar con el nombre de "CubeSat Design Specification", correspondiente a la definición de un sistema modular de dimensiones cubicas de $10 \mathrm{~cm}$ de lado y con una masa básica de $1.33 \mathrm{~kg}$ (tabla 2), donde los pico satélites representarían una categoría adicional de menos de $1 \mathrm{~kg}$ de masa, a pesar de poder tener el mismo dimensionamiento físico de una unidad de CubeSat o tamaños más reducidos, como se están generando actualmente en países como la India.
Tabla 2.

Clasificación de pequeños satélites

\begin{tabular}{lc}
\hline \multicolumn{1}{c}{ Tipo de satélite } & Masa \\
\hline Minisatélite & $500-100 \mathrm{~kg}$ \\
\hline Microsatélite & $100-10 \mathrm{~kg}$ \\
\hline Nanosatélite (CubeSat) & $10-1 \mathrm{~kg}$ \\
\hline
\end{tabular}

Fuente: Radhakrishnan et al., 2016.

Con base en estos desarrollos modulares, se puede apreciar en la figura 11 la diferencia estructural entre un tipo de satélite tradicional convencional de gran escala conocido como monolítico, con respecto a otros de pequeña escala que pueden ser configurados en infraestructuras modulares fraccionadas o desagregadas con la disposición de la misma carga útil, pero con elementos adicionales de configuración en red para suplir el servicio.

Por consiguiente, las líneas de producción trabajan con base a los requerimientos dimensionales de los satélites (figura 12), donde se pueden apreciar las diferentes configuraciones de tamaño y capacidad de equipos a bordo, desde la unidad básica cubica $1 \mathrm{U}$ con dimensionamiento aproximado de $10 \mathrm{~cm}$ de lado, hasta el acoplamiento 


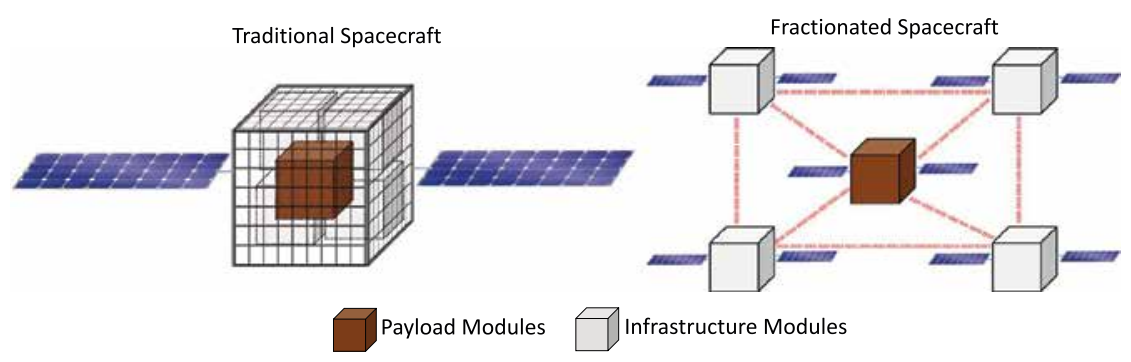

Figura 11. Diferencias artefactos espaciales Fuente: Poghosyan y Golkar, 2016.

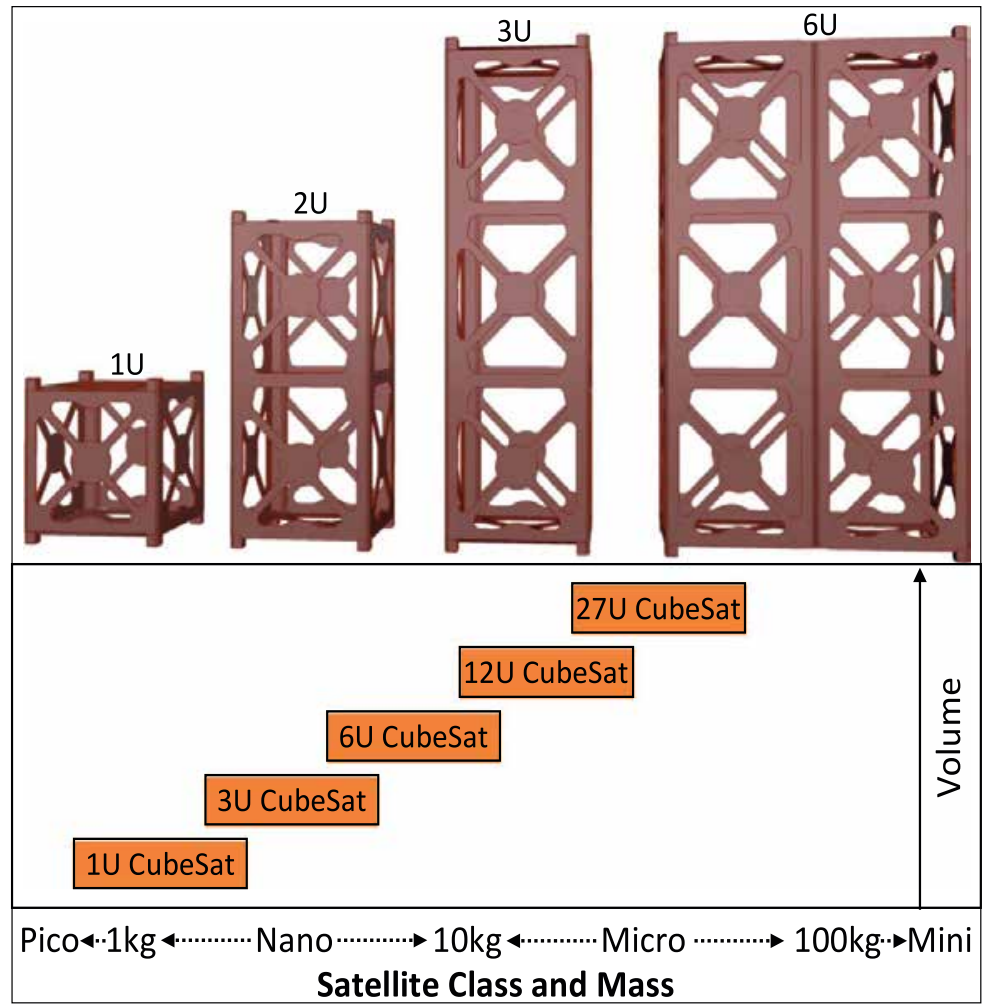

Figura 12. Configuraciones básicas de CubeSat Fuente: Poghosyan y Golkar, 2016.

modular $6 \mathrm{U}$ o 12U, según sea el caso de dispositivos y funciones particulares de cada misión.

Tomando como referencia dichas capacidades y dimensionamientos, en la figura 13 se puede apreciar el incremento en la tendencia de uso de la configuración $3 \mathrm{U}$ o de tres CubeSat integrados, la cual permite tener varios sistemas a bordo, especialmente el uso de cámaras multiespectrales como carga útil especial para amplias aplicaciones.

Por otra parte la operación de sistemas y provisión de servicios esta enlazada a diferentes tecnologías con relación a las bandas VHF, UHF, Banda-S entre otras, con las que operan los equipos en órbita (Bouwmeester y Guo, 2010), así como soluciones alternativas para sistemas de pruebas en tierra (Mier y Lozano, 2017), que en complemento con las bandas de operación de los sistemas satelitales viabilizan el procesamiento de datos para los diferentes servicios.

De igual manera, la operatividad de cualquier sistema satelital, requiere de un proceso de diseño de misión para la definición de requisitos y especificaciones de todos los subsistemas y segmentos de trabajo, como es el caso de identificar las diferentes bandas de entrada o de salida de comunicaciones con características de canal específcas y márgenes de trabajo de los enlaces de transmisión, 


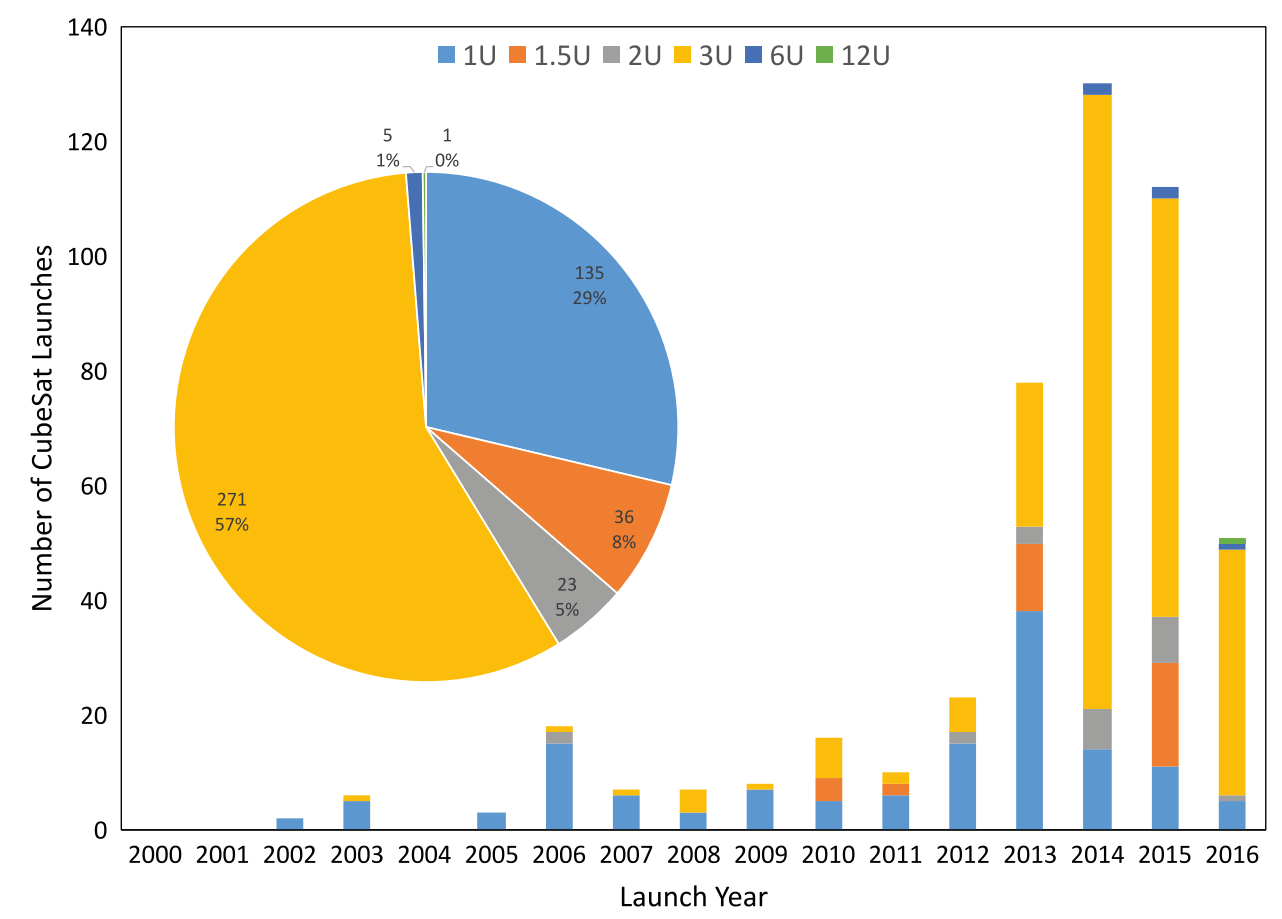

Figura 13. Lanzamientos de sistemas CubeSat Fuente: Poghosyan, y Golkar, 2016.

recepción y ruido del sistema en banda-S, banda Ka, entre otras (Álvarez y Walls, 2016).

Adicional al uso de frecuencias y su administración, es de resaltar que los procesos encaminados a la prestación de servicios aeroespaciales pueden planearse a partir de un diseño de misión del segmento espacial, con las especificaciones del segmento donde se realizarían las operaciones y con las posibilidades de participación de un sinnúmero de empresas dedicadas al acompañamiento y formulación de estrategias para la prestación de los servicios (Lowe y Macdonald, 2014).

Además de las estructuras modulares, el diseño de misión o las características de las bandas de comunicación requeridas en la configuración de sistemas satelitales en red, las agencias y proveedores de servicios aeroespaciales toman en cuenta los sistemas de referencia como el de la fundación para agentes físicos inteligentes (FIPA) (Chen, Linz y Cheng, 2008), y demás estándares de operación formalizados por las agencias de mayor impacto mundial como la Administración Nacional de la Aeronáutica y del Espacio (NASA), la Agencia Espacial Europea (ESA), y actualmente la gestión significativa de países como India y China, en la administración de recursos espaciales y desarrollo de nuevas tecnologías y misiones de sistemas satelitales de pequeña escala (tabla 3), frente a los lanzamientos realizados o proyectados de sistemas en red.
Un ejemplo práctico del diseño de misión y de segmentos para la disposición de satélites en órbita es la configuración de arquitectura que identifica tendencias entre desempeño y costos de ciclo de vida con respecto a las variables de decisión, como lo son la inclinación y la altitud de la órbita para la operación de los satélites, todo mediante el diseño de un modelo rápido de diseño interdisciplinario para la misión de CubeSat (Lowe y Macdonald, 2014).

Como complemento a estas consideraciones, en Latinoamérica y en Colombia particularmente, también se han trazado búsquedas para la apropiación de estas tecnologías, con lo cual se han vinculado tanto la empresa privada como la pública, además de varias universidades, con equipos de trabajo en temas aeroespaciales.

Como la Universidad Sergio Arboleda con la estructuración y lanzamiento del proyecto Libertad 1, en el año 2007 y el diseño de misión del Libertad 2, o la Universidad de los Andes, la Universidad Nacional de Colombia, la Universidad Distrital, la Universidad del Valle o la Universidad Los Libertadores, entre otras, con sus grupos de cohetería y temas espaciales han trazado líneas de acción para la ruta espacial colombiana, como la empresa Secoia en su participación y aportes dentro del sector.

Por su parte, la institucionalidad pública aporta planes de desarrollo con la proyección de lanzamiento del primer 
CIENCIA Y PODER AÉREO | ISSN 1909-7050 | E-ISSN 2389-9468 | Vol. 13 | Núm. 2 | Jul - Dic 2018 | Escuela de Postgrados de la Fuerza Aérea Colombiana | pp 90-125

Tabla 3.

Reporte de misiones múltiples de satélites pequeños

\begin{tabular}{|c|c|c|c|c|c|}
\hline Mission name & $\begin{array}{c}\text { Number of small } \\
\text { satellites }\end{array}$ & $\begin{array}{l}\text { Mass of small } \\
\text { satellites }(\mathrm{Kg})\end{array}$ & Inter-satellite links & $\begin{array}{c}\text { Inter-satellite } \\
\text { communication } \\
\text { approach }\end{array}$ & $\begin{array}{c}\text { Launched/ } \\
\text { Projected launch } \\
\text { year }\end{array}$ \\
\hline GRACE & 2 & 480 & Available & RF based (S-band) & 2002 \\
\hline ESSAIM & 2 & 120 & Not available & Not available & 2004 \\
\hline PRISMA & 4 & 145,50 & Available & $\begin{array}{c}\text { RF based } \\
\text { (UHF-band) }\end{array}$ & 2010 \\
\hline ELISA & 4 & 130 & Not available & Not available & 2011 \\
\hline EDSN & 8 & 1.7 & Available & $\begin{array}{c}\text { RF based } \\
\text { (UHF-band) }\end{array}$ & 2015 \\
\hline QB-50 & 50 & 2,3 & Available & RF based (S-band) & 2016 \\
\hline PROBA- 3 & 2 & 320,180 & Available & RF based (S-band) & 2017 \\
\hline eLISA & 3 & To be deterrnined & Available & $\begin{array}{c}\text { Optical based } \\
\text { (LASER) }\end{array}$ & 2028 \\
\hline MAGNAS & 28 & 210,5 & Available & $\begin{array}{c}\text { RF based } \\
\text { (UHF-band) }\end{array}$ & To be determined \\
\hline
\end{tabular}

Fuente: Radhakrishnan et al., 2016.

satélite de pequeña escala, formulado para el ejercicio de soberanía nacional, además del diseño de misión de una segunda fase, planeados como las bases de operación formal del sistema satelital colombiano, que demandaría la operación de satélites de pequeña escala y requerimientos de sistemas de control en red, con la necesidad específica de coordinar capacidades distribuidas en dichos satélites.

Al respecto se pueden considerar estudios puntuales como apoyo a la prospectiva del sistema satelital colombiano, tales como la determinación de actitud para un satélite tipo CubeSat realizado por la Universidad Distrital (Castellanos, Edith y Pico, 2014), donde se aplica el filtro de Kalman extendido, mediante el método de Runge-Kutta, a través de la matriz de transición de estados tradicional.

Así como los diseños de orbita para la disposición de soluciones satelitales al sistema colombiano, con enfoque a la integración de operaciones interagenciales y servicios complementarios (Poveda, 2016), siendo uno de los elementos fundamentales para el diseño de misión, en la cual se determinan los demás subsistemas y condiciones de vuelo y de lanzamiento de las plataformas satelitales, ya sea en alguna de las órbitas típicas, como se relacionan a continuación:

- Baja 100-1.500 km aprox.

- Media 1.50010 .000 km aprox.

- Geoestacionario.

En referencia a estas órbitas, se han ampliado los contextos para el uso de sensores de percepción remota de diversa índole como carga útil factible a dichos servicios, referido específicamente al desarrollo de cámaras multiespectrales como lo ilustra la Universidad Sergio Arboleda, (Alex, Viviana, Torres y Sebasti, 2014).

\section{Arquitecturas satelitales}

Luego de las descripciones generales del estado actual de las tecnologías de pequeña escala, requerimientos, servicios y gestores aeroespaciales, a continuación se presentan varias de las arquitecturas con las que son configurados los satélites para diferentes tipos de misiones, destacando los componentes sobre los cuales se establecen las configuraciones de red y donde se formulan los diseños de topologías y control de agentes de la red.

\section{Estructura general satelital}

Dentro de las arquitecturas de satélites más comunes y descritas de forma genérica, se relacionan los siguientes subsistemas:

- Estructura.

- Sistema de propulsión.

- Sistema de potencia o energía.

- Sistema de comunicaciones.

- Sistema de control.

De manera detallada donde se enlazan los subsistemas de la estructura básica de un satélite de pequeña escala, gráficamente se tiene como referencia la figura 14, donde se le da la relevancia a la carga útil como elemento 


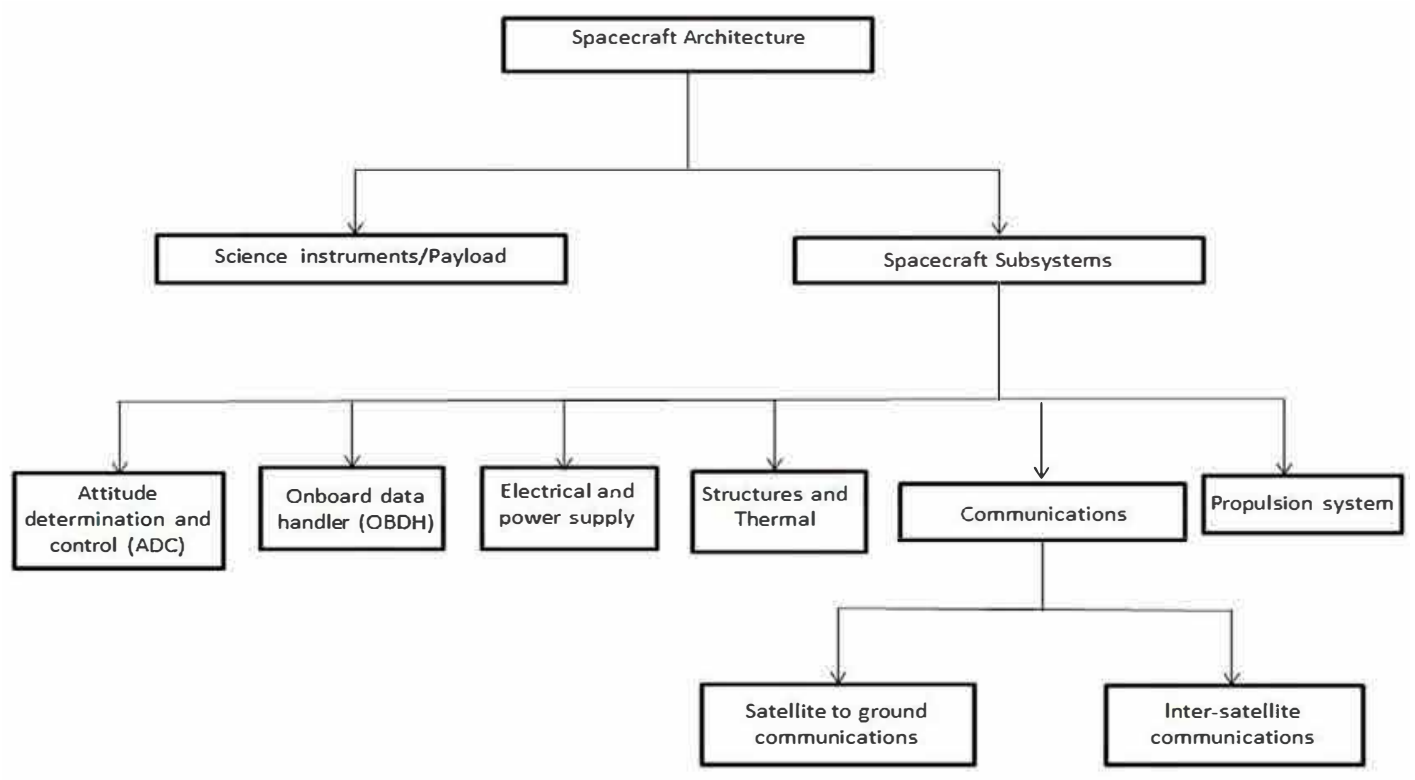

Figura 14. Arquitectura general de un equipo satelital Fuente: Radhakrishnan et al., 2016.

determinante de la arquitectura satelital, además de los subsistemas categorizados por funciones y dentro de estos el de comunicaciones, que determina formalmente la actuación de redes con equipos en tierra, o con equipos en constelaciones, o clúster con los se constituyen los sistemas de control en red.

\subsection{Sistemas automatizados}

En términos comparativos, los sistemas satelitales vinculan la integración de tres tópicos fundamentales, descritos de manera escalonada y comparada a los sistemas automatizados.

Como lo son los niveles de la automatización que involucran un primer nivel dedicado a los sistemas de actuación y sensado, donde se definen los subsistemas de medición, sensores, toma de señales, protocolos de comunicación, entre otros. Un segundo nivel descrito por las capacidades de control y supervisión con las configuraciones para el uso de los sistemas de actuación, junto con los esquemas y modos de verificación y monitoreo de estos. Un tercer nivel descrito por los sistemas de planeación, gestión logística y operativa, que buscan garantizar la programación y ejecución efectiva de las misiones.

En primer lugar, se tiene el diseño y análisis de capacidades y equipos a bordo de cada satélite o agente, con lo cual se logra la identificación, caracterización y actuación de cargas útiles y configuración de sensores, donde la fusión sensorica cobra significado frente a la estimación de errores, planificación de trayectorias y seguimiento a pa- rámetros de operación, teniendo en cuenta la estimación de estados de acuerdo a las últimas actualizaciones del sistema. Así como, las señales de comando generadas en las interfaces y de forma integral la estimación de respuesta de los demás subsistemas relacionados con la estabilidad de los agentes.

En este sentido, la fusión sensórica combina las observaciones y mediciones de diferentes sensores que configurados, según la misión de vuelo, proveen los recursos necesarios para la toma de decisiones y asignación de tareas en los resultados finales de la coordinación de los agentes.

En segundo lugar, el diseño de controladores específicos para sistemas homogéneos y heterogéneos conectados en red, puesto que la necesidad de suplir los servicios con múltiples equipos requiere la capacidad de controlar cada agente con sus propios recursos, así como la capacidad de coordinar los agentes entre ellos, ya sea que tengan homogeneidad en su configuración o sean heterogéneos en la disposición de sus recursos de vuelo.

Las configuraciones o topologías de red son la base para el planteamiento de nuevos sistemas de control, donde precisamente se centraría la propuesta respecto al diseño de controladores capaces de coordinar agentes con diferentes capacidades y misiones de vuelo.

Finalmente, se tiene el tercer tópico, el cual involucra la definición de los sistemas según la planeación y estimación logística de los agentes, buscando así la estructuración 
de la red satelital, la gestión de recursos y la definición del sistema de control requerido para la misión asignada del clúster o la constelación, tales como lograr la definición del servicio aeroespacial del sistema multiagente, para la toma de imágenes, comunicaciones, monitoreo, entre otras posibilidades disponibles según sea la necesidad de la red multiagente, como el caso de la definición de parámetros para la ingeniería de potencia (Moradi, Razini y Hosseinian, 2016).

\section{Tendencias de las configuraciones satelitales}

De acuerdo a los reportes identificados en las bases de datos de producción y tendencias en el desarrollo aeroespacial (Medina, 2017), las configuraciones satelitales de pequeña escala apuntan a tres tópicos diferenciados entre sí, como lo son las comunicaciones, el control electrónico y la estructura y propulsión, con los subsistemas como se relaciona a continuación.

\section{Comunicaciones:}

- $\quad$ Sistemas de carga útil y sensores.

- Sistemas de almacenamiento y procesamiento de datos.

- $\quad$ Sistemas de comunicación y telemetría.

\section{Control electrónico:}

- Sistemas de control de navegación.

- $\quad$ Sistemas de control electrónico.

- Sistemas de alimentación eléctrica.

Estructura y propulsión:

- $\quad$ Sistemas de control térmico.

- $\quad$ Sistemas de propulsión.

- $\quad$ Sistemas de estructuras espaciales.

En la figura 15 se puede observar la dinámica tecnológica de las tendencias en actividades de inventiva dentro

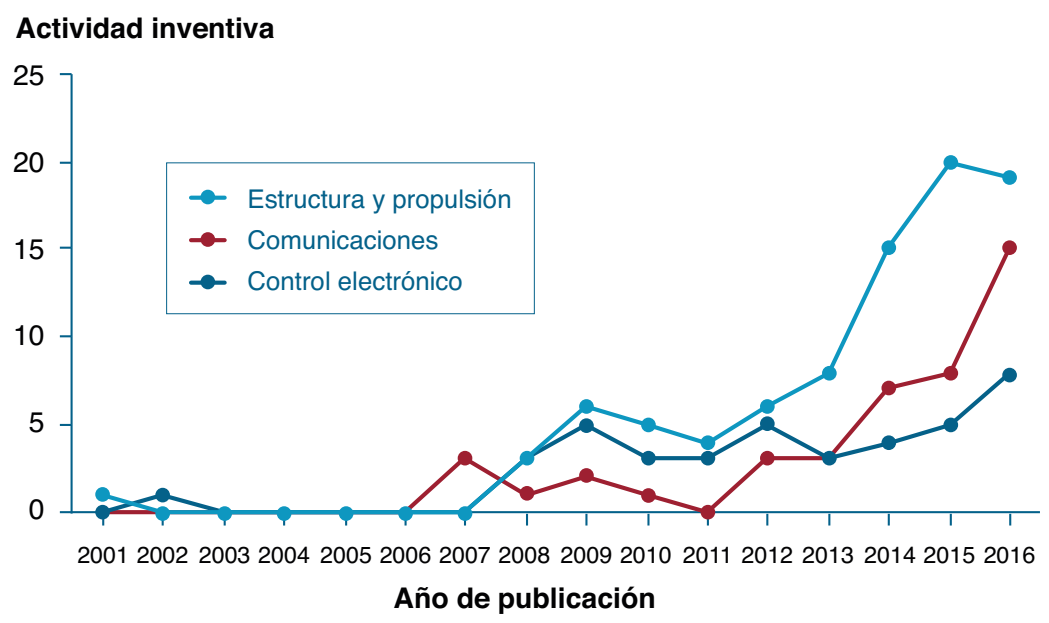

Figura 15. Dinámica tecnológica de las tendencias identificadas

Fuente: Medina, 2017, tomada de Thomson Innovation, Espacenet, USPTO, Latipat, entre otras.

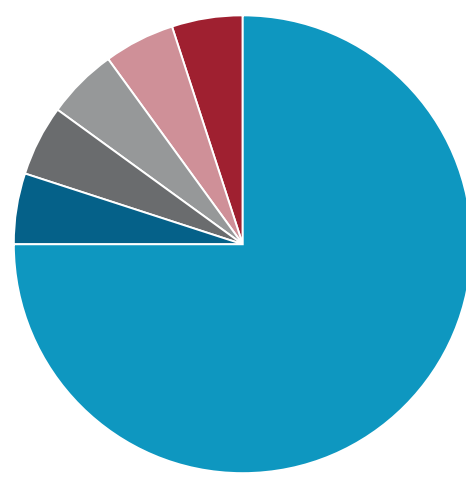

(Telemetría, seguimiento y sistemas de mando)

Figura 16. Consumo promedio de energía eléctrica de un satélite Fuente: Medina, 2017. 
de las tres configuraciones, en las cuales los estudios de estructura y propulsión representan el mayor porcentaje de producción científica, aunque la tendencia de los estudios en comunicaciones representa una mayor pendiente de interés que hacia los próximos años puede superar las actividades de invención.

Se puede apreciar en la figura 16, que los sistemas de comunicación son los que más demandan consumo de energía a bordo, razón por la cual se puede correlacionar la tendencia en el incremento de las invenciones en subsistemas de comunicaciones que logren mayor eficiencia y que extiendan la vida útil de los demás subsistemas.

\section{Sensores y actuadores}

De forma particular en las figuras 17 y 18 se pueden observar los diferentes actuadores o estabilizadores a bordo como los posibles sensores a ser configurados en cada satélite, según sean sus funciones específicas de operación.

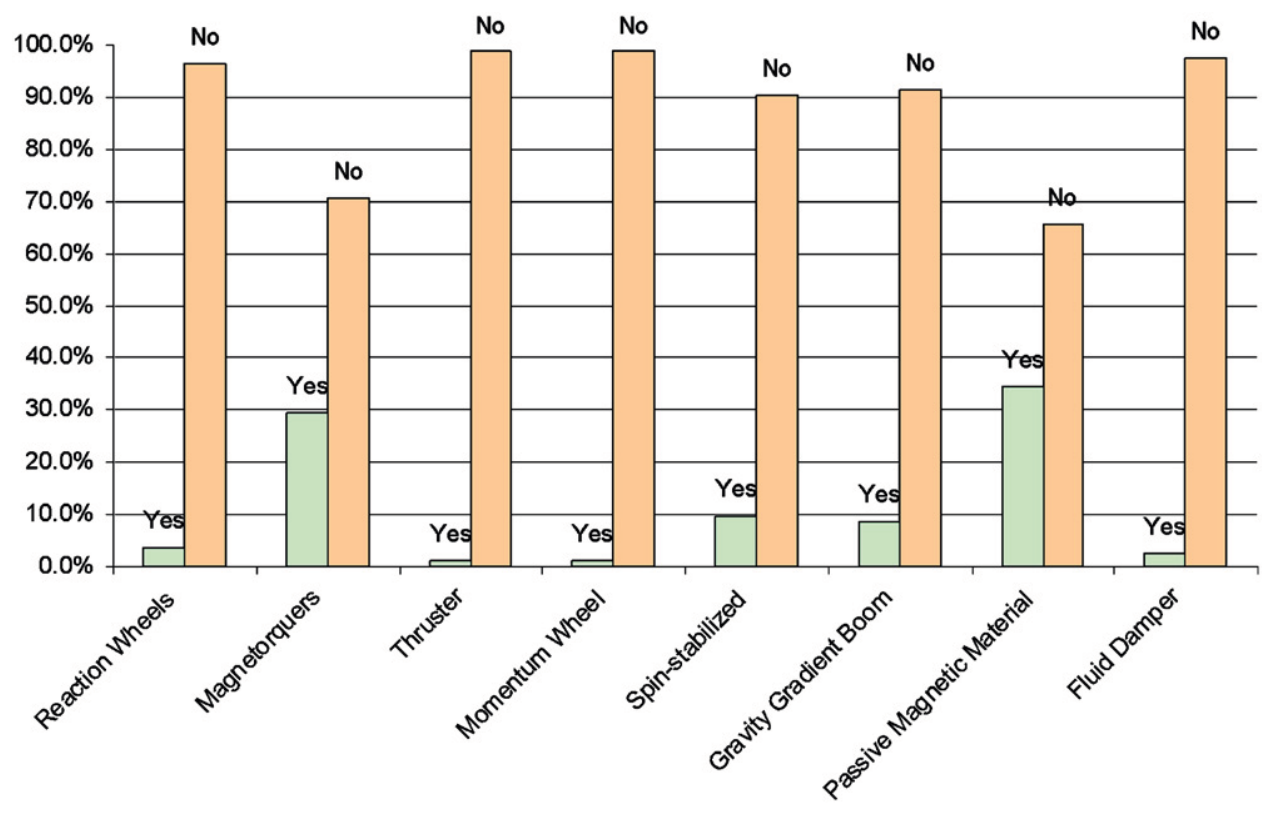

Figura 17. Actuadores o estabilizadores a bordo Fuente: Bouwmeester y Guo, 2010.

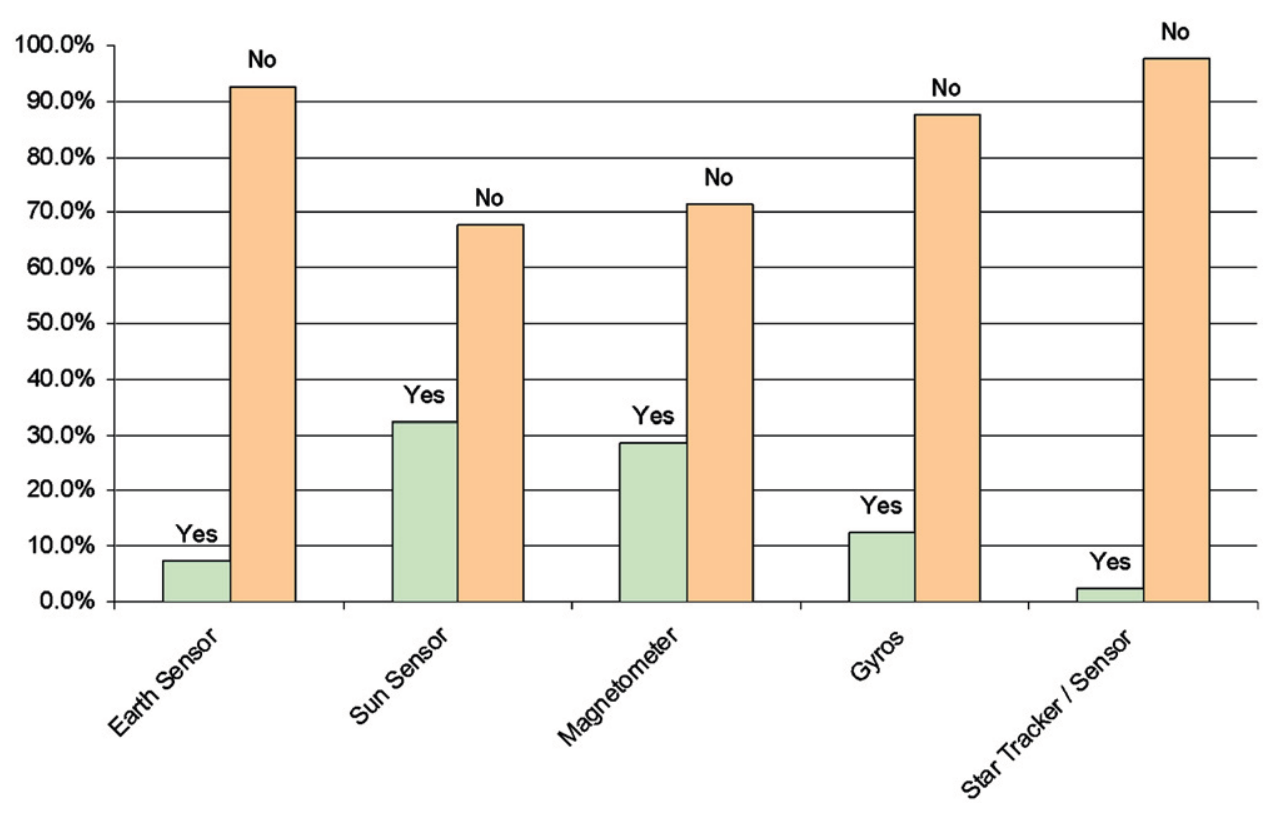

Figura 18. Sensores de actitud abordo Fuente: Bouwmeester y Guo, 2010. 
Como aplicación particular de los sensores en sistemas de control en red, se han trabajado sistemas de micronavegación GPS y sistemas de comunicación para clúster de micro y nanosatélites, donde plantean las configuraciones de técnica doble completa y técnica simple para transmisión y recepción en el acceso múltiple de datos (Zenick y Kohlhepp, 2001).

Por su parte, en el concepto de las comunicaciones entre satélites pequeños, según la figura 19, se ha integrado la ingeniería de sistemas a través del modelo de interconexión de sistemas abiertos (OSI) con el diseño receptivo y formal (RFD), como se relaciona a continuación con el marco de referencia general.

Adicionalmente en la figura 20, se ilustra una arquitectura y esquema de orientación integrada de navegación y control, para la interconectividad de agentes dentro de una red.

Retomando entonces los diferentes componentes de un sistema satelital, se puede abordar la configuración de cada agente junto con los requerimientos propios de la red, según sea el grafo de conectividad o las misiones tipo que sean solicitadas desde la estación en tierra.
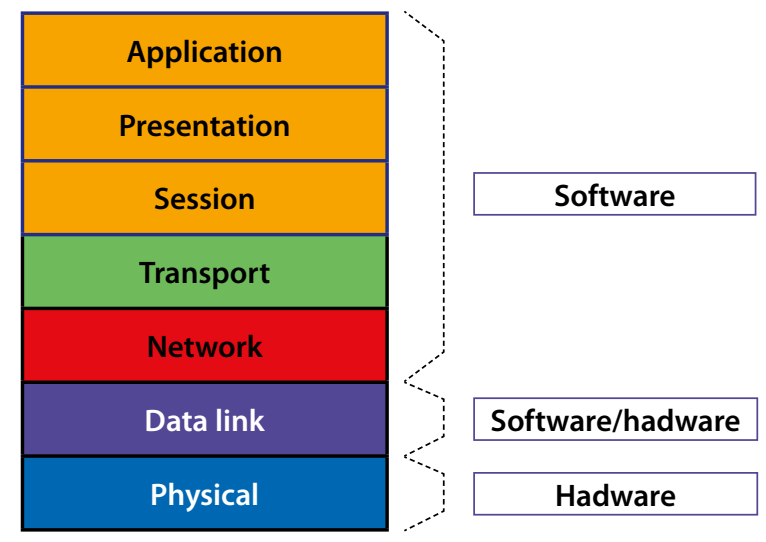

Figura 19. Marco de referencia de las comunicaciones intersatelitales Fuente: Radhakrishnan et al., 2016.

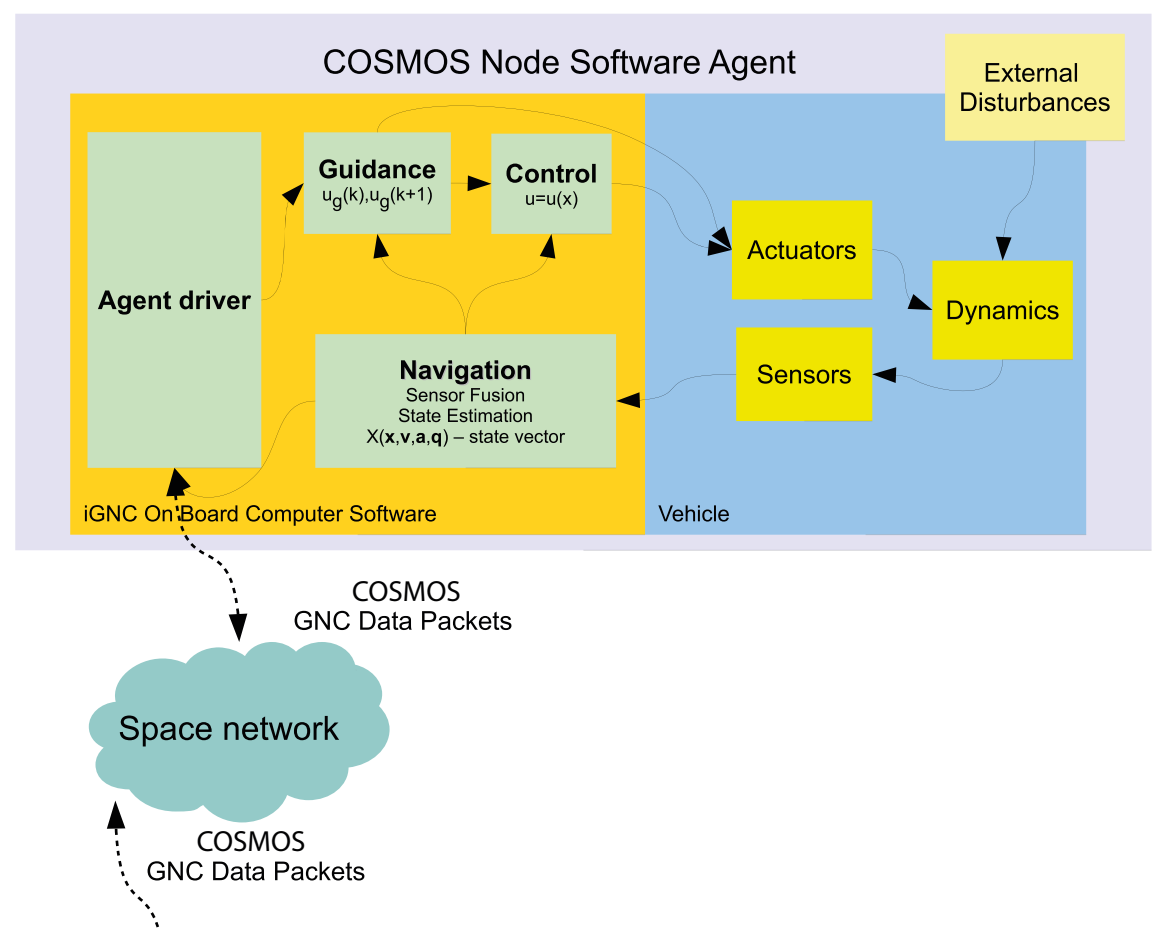

Figura 20. Esquema de orientación integrada de navegación y control Fuente: Sorensen, 2014. 


\section{Modelos de referencia}

Posterior a la descripción de arquitecturas con las que se define la capacidad del diseño de misión de múltiples satélites en red, se requiere la identificación de modelos sobre los cuales se estructure la topología de red, la coordinación de funciones y delegación de tareas de la red, entre otras especificaciones útiles para el diseño y control de esta.

Uno de los puntos de interés para el desarrollo de modelos matemáticos, es la concepción del problema de consenso, a partir del cual se establecen condiciones para la coordinación de sistemas multiagente, considerando el control de formación, el control de actitud y el comportamiento de encuentro en términos de velocidades, conectividad y puntos de acuerdo, referidos con la dinámica multiagente y los algoritmos de consenso, descritos en topologías y dinámica compleja de problemas en red (Taylor, Wang, Gao, Alsaadi y Hayat, 2014).

Varios de los aspectos relevantes para el control de actitud de los satélites se ilustran en la figura 21, donde la coordinación y adecuada formulación del modelo de los sistemas de instrumentación, comunicaciones con la estación en tierra, sistemas de almacenamiento de energía y hasta los medios de rotación del satélite, que implican la integración de técnicas de control capaces de administrar los recursos a bordo y lógicamente mantener la conectividad de la red con la operación de todos sus agentes y sus recursos.
Otro enfoque del problema de consenso en sistemas multiagente, refiere la descripción matemática como primer interés, los protocolos de consenso, el análisis y velocidad de convergencia, el equilibrio de estado, el problema de consenso en redes complejas, el filtro de consenso, las configuraciones de enjambre y puntos de encuentro de los sistemas multiagente hasta el control de formación de estos (Ren, Beard, Atkins y Theory, 2005).

Un modelo en tiempo discreto para $\mathrm{n}$ agentes, consiste en la actualización de las reglas locales de los vecinos más cercanos dentro de una red, con lo cual se logra una coordinación centralizada al comportamiento de los agentes cercanos. Mediante el método de Vicsek para la estabilidad de sistemas lineales conmutables, (Jadbabaie, Lin y Morse, 2003)

El modelo anterior es también aplicado al problema de consenso con la formulación de un modelo de alta fidelidad de linealización para el factor de achatamiento en los polos de la tierra (J2) en formaciones de satélites (Sedwick, Supervisor, Miller y Velde, 2001), con el uso de la ecuación de Hill como ecuación de movimiento (Sorensen, 2014), mediante el uso de la matriz de transición de estado discreta basada en la ecuación que es usada para obtener el sistema dinámico linealizado como un estado linealizado de propagación, tomando como referencia el proyecto TechSat21 (Martín, 1997), con la geometría y control de formación satelital.

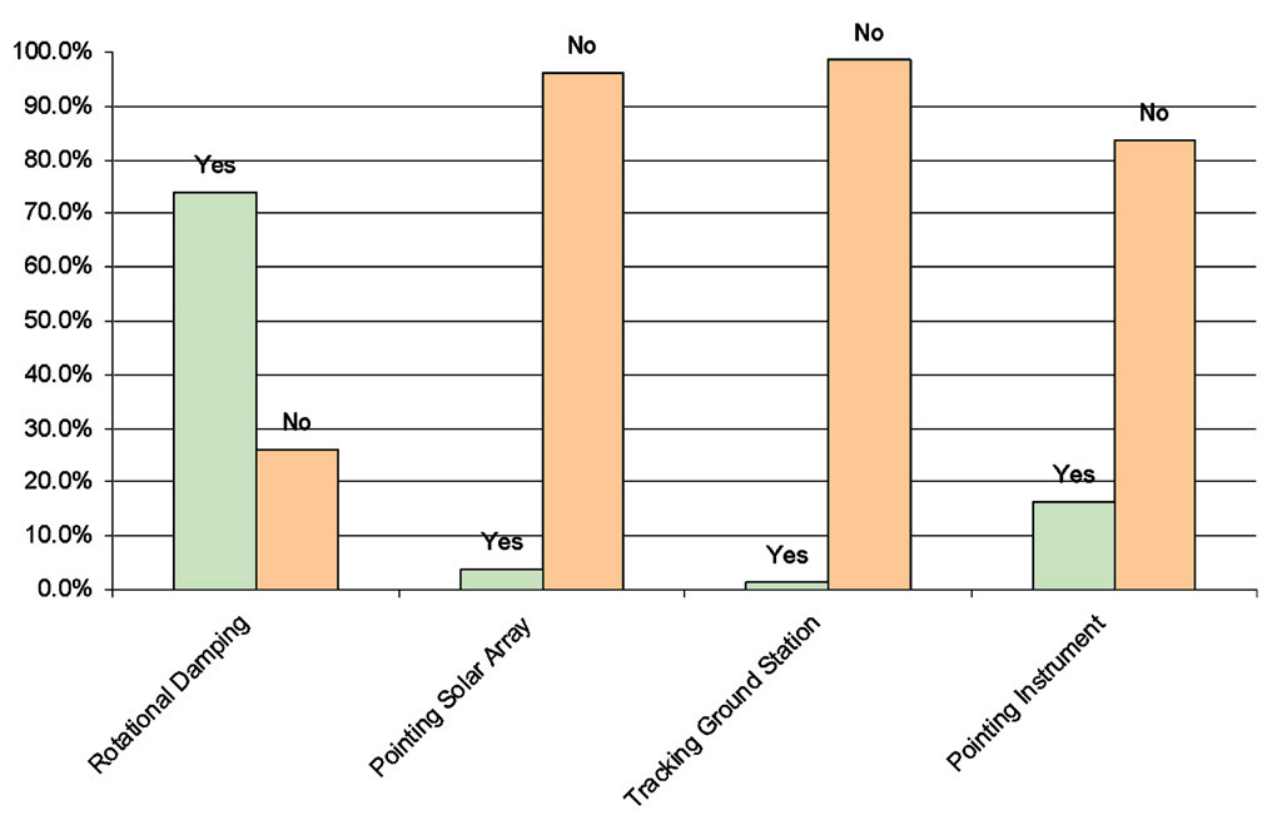

Figura 21. Objetivos de control de actitud Fuente: Bouwmeester y Guo, 2010. 
Para la órbita LEO, se considera el movimiento relativo descrito afectado por el factor también llamado de población de la tierra J2, con el modelamiento de los ejes $x, y, y z$ del satélite en función del tiempo.

Por otra parte, se aplica el regulador cuadrático lineal (LQR) para llegar al modelo generalizado, vinculando la simulación de posición y rendimiento de las maniobras por redezvous (Sorensen, 2014).

Otros desarrollos propuestos para el control de constelaciones se basa en el método de optimización por algoritmos genéticos, para observación de la tierra, con la estimación de parámetros por decodificación de estados (Nunes, 2015). Este algoritmo se basa en el método de penalización de la función a través de multiplicadores de Lagrange, donde se busca la optimización del sistema con la minimización de los siguientes parámetros:

- Número de planos orbitales entre los grupos de satélites.

- Número de satélites por plano orbital.

- Número de grupos de satélites.

- Ángulo de separación entre planos orbitales de grupos.

- Ángulo de separación entre satélites.

- Ángulo de separación de primeros satélites en cada clúster.

Llegando así a un valor de la función objetivo que optimiza el número de satélites frente a una misión específica de funciones.

Una alternativa planteada de solución para formaciones satelitales basada en la ecuación de Hill, se fundamenta en superficies geométricas simples, tomando como base un satélite líder en una órbita circular determinada por la intersección de planos para el ajuste de dispositivos de sensado (Yeh, Sparks y Force, 2000). De tal manera que ante las perturbaciones puedan reposicionarse en la formación, quedando incluidos los términos de fuerza y distorsiones, con trayectorias de referencia específicas.

Otro modo de control resultante del análisis de misiones satelitales, es el control electromagnético de las ruedas de reacción en una formación de dos o más satélites dentro de un arreglo, con parámetros de actualización, masa, energía, eficiencia, encendido, entre otros, que conducen hacia la función de rotación de cada satélite, para optimizar el sistema de propulsión en consumo para la formación, (Yeh et al., 2000; Kong et al., 2004).
Un ejemplo de control de formaciones mediante fuerzas electromagnéticas, muestra el concepto de misiones interferométricas, para la cooperación de los miembros del sistema multisatélite (Wawrzaszek y Banaszkiewicz, 2007), con lo cual se controlan los sistemas respecto a las fuerzas requeridas para la actuación de valores de reconfiguración de la red, suficientes para activar la propulsión de uso disponible manteniendo la seguridad de la red.

Como resultado de las interacciones entre satélites como agentes de una red, también se han planteado algoritmos de consenso y cooperación en redes de sistemas multiagente, donde se privilegia el papel del flujo de información en la red y se proponen topologías de red, para retardos de tiempo, nodos o enlaces con fallas, con el fin de garantizar el desempeño de conectividad del sistema multiagente.

En estos trabajos se vinculan soluciones para el problema de consenso, a partir de las teorías de control, grafos y variables de estado, para proponer interacciones de sistemas distribuidos con vecinos cercanos y disponibilidad de flujos de información en diferentes localidades de la red (Olfati, Fax y Murray, 2007).

\section{Sistemas de control en redes satelitales}

Habiendo revisado los modelos de referencia para los satélites y sus posibles configuraciones en red de forma general, a continuación se relacionan aplicaciones puntuales a los sistemas de formación satelital, tomando como base el modelo de referencia ilustrado en la figura 22 , donde se presenta la arquitectura general de los sistemas de control en red, a partir de la conectividad de agentes, con diferentes procesos de interacción, fusión sensorica y control basado en optimización para la operación entre agentes.

En este sentido, se toman como referencia diferentes diseños de misión, a partir de los cuales se buscó la integración de agentes y funciones de control en red.

\section{Diseños de misión de redes}

Desde el año 1999 la NASA proyectó alternativas de bajo costo respecto a plataformas de control distribuido sobre arquitecturas virtuales de pequeños satélites en red, las cuales son caracterizadas por la cooperación y los comportamientos comunes entre satélites, tanto en constelaciones como en formaciones.

Es decir, se han considerado atributos colectivos y capacidades individuales dispuestas en red como lo ilustra la figura 23, desde las que se visualizaron las ventajas de explotación de uso y aprovechamiento de estas redes, tanto en la NASA como en el Departamento de Defensa de los Estados Unidos. (Weidow, Bristow y Weidow, 1999). 


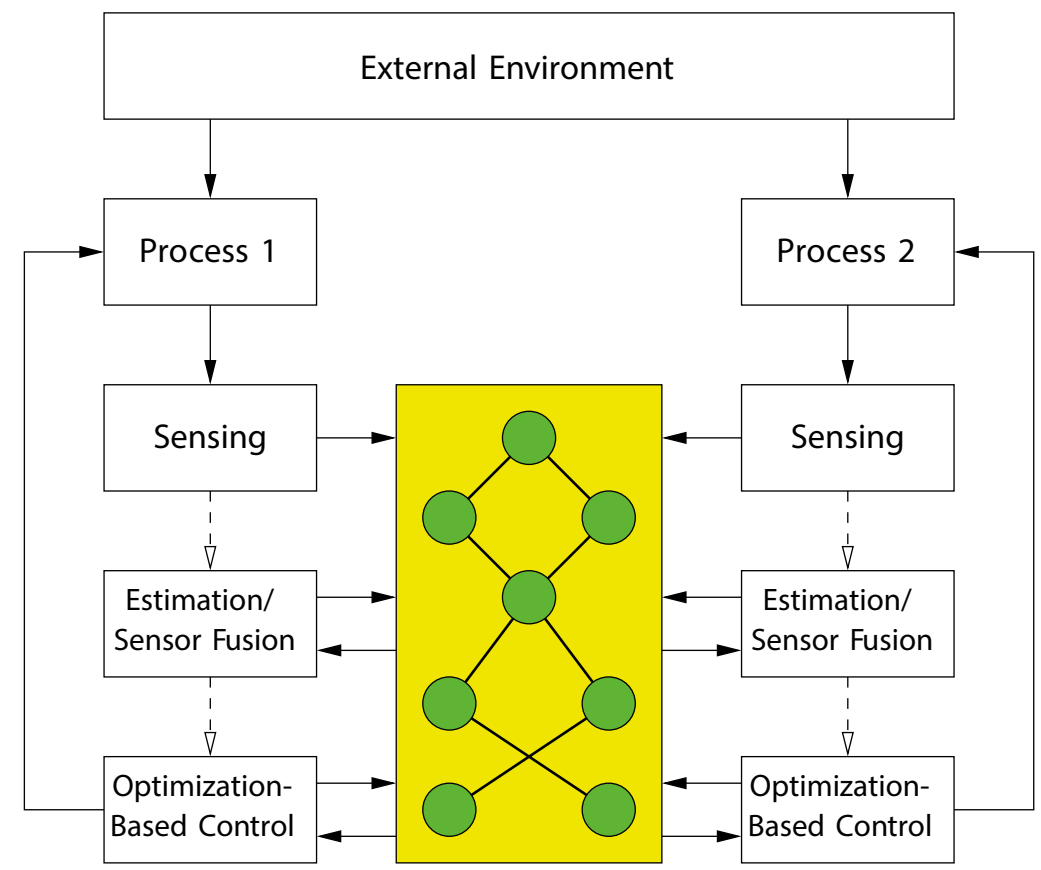

Figura 22. Arquitectura de control para sistemas de control en red Fuente: Murray, 2016.

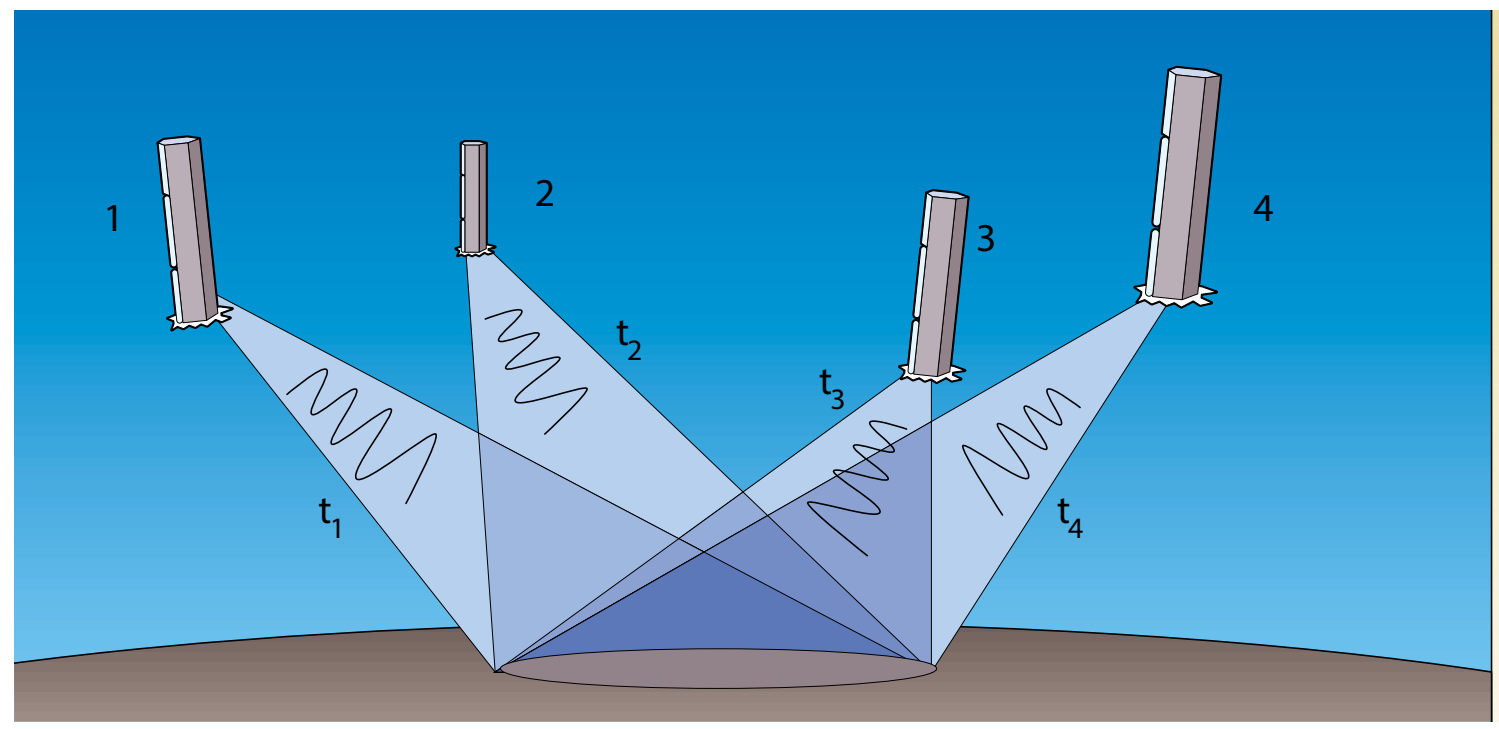

Figura 23. Matriz de escasa apertura Fuente: Zetocha et al. 2000.

Especialmente el laboratorio de investigaciones de la Fuerza Aérea de los Estados Unidos por medio de su programa TechSat21 (Martín, 1997), junto con la empresa DARPA y otras 10 universidades americanas, trabajaron en el desarrollo del concepto de nanosatélites desde el año 1997, con lo cual se realizó el lanzamiento de los 10 nanosatélites proyectados en el 2001, a partir de un diseño de misión en cuatro pasos, con referencia de la estación en tierra (figura 24).

El primero relacionado con la unión de las universidades y los equipos de trabajo del Departamento de Defensa y la NASA, el segundo se enfocaba al desarrollo de los sistemas de comunicación entre satélites, el tercero introducía 


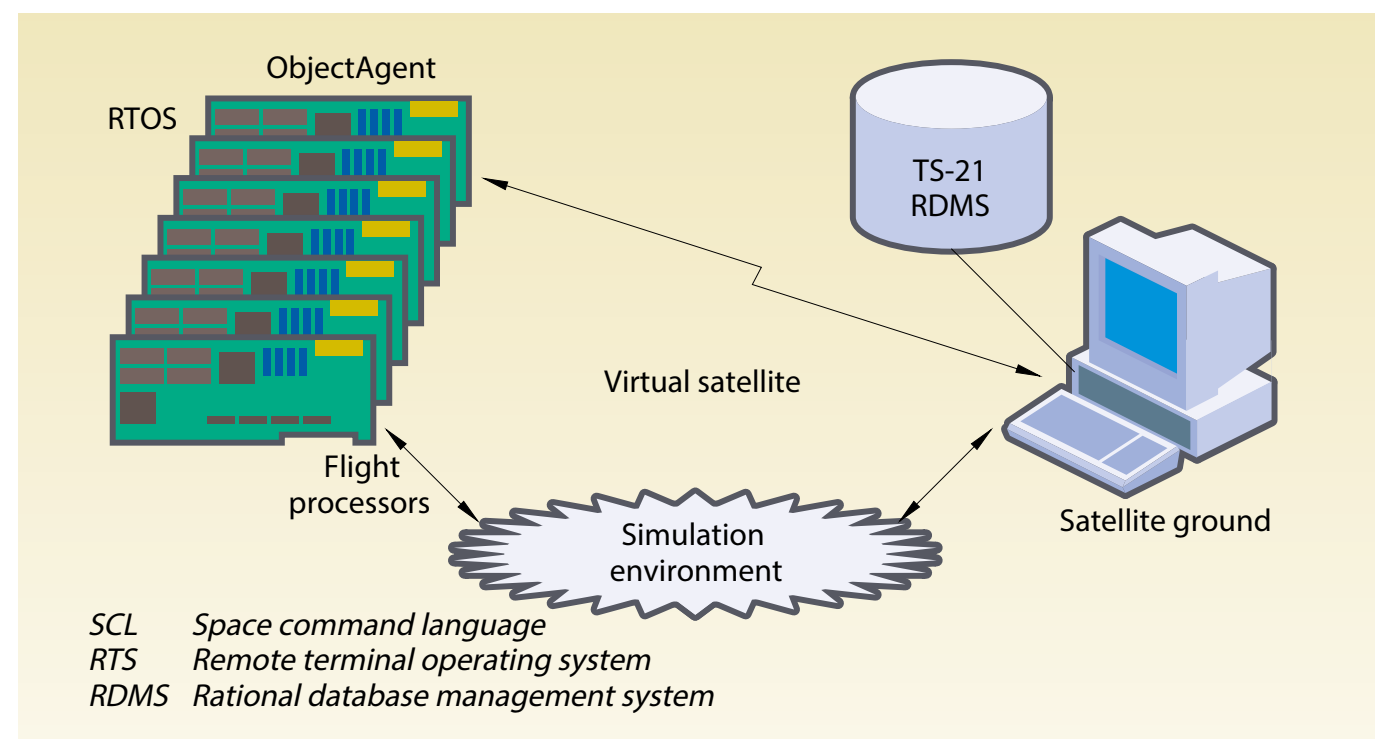

Figura 24. Esquema estación en tierra TechSat21 Fuente: Zetocha et al., 2002.

el sistema de navegación y un cuarto paso referido al desarrollo de sistemas de control de formación, fueron básicamente los primeros pasos en el abordaje de estos conceptos respecto a su utilización en sistemas satelitales de pequeña escala, incluyendo dentro de estas aplicaciones el concepto de pruebas y validaciones de manera paralela. (Weidow et al., 1999).

Una aplicación adicional es la operación del FormSat (Braukhane et al., 2010) mediante la cual se plantea un modelo de negocio en torno a la operación de servicios satelitales y de manufactura de estos, con los cuales se dispongan diferentes cargas útiles para cada servicio, o el proyecto SAMSON, mediante el cual se presenta un modelo de vuelo de clústeres satelitales con la geolocalización de tres nanosatélites dentro de un segmento espacial, segmento de tierra, segmento de usuario y segmento de lanzamiento (Gurfil, Herscovitz, Pariente, 2014),

Por otra parte, se presentan avances como la red espacial QB50 con capacidades de hasta 50 nanosatélites y formación de vuelo equipados con carga útil para estudios científicos, en desempeño multipunto y mediciones in situ en la termosfera baja, buscando con esto la compensación de la resistencia diferencial y el control relativo del vector de excentricidad e inclinación de la formación satelital, (Gill, Sundaramoorthy, Bouwmeester, Zandbergen y Reinhard, 2013).

Adicional al control de capacidades de carga útil, se han desarrollado controles cíclicos on off para vuelo de clústeres satelitales, donde se ajusta la operación de los sistemas de propulsión para mantener las distancias de re- ferencia de los satélites dentro de una formación descrita con topologías de red en anillo (Zhang y Gurfil, 2015).

Otra aplicación de los clúster de nanosatélites se presenta con los estudios de múltiples satélites en la región de aceleración auroral, donde los focos de estudio son las propiedades quasi estáticas, características espaciotemporales, estructuras del potencial eléctrico, entre otras que mediante la fusión sensorica a bordo en los satélites provean la información necesario con alta redundancia y consistencia de datos, con clúster de 6 a 12 CubeSat, que en periodos cortos de tiempo pueden tomar la información requerida o ajustar el concepto de misión (Sadeghi y Emami, 2017).

De manera complementaria también se han descrito las necesidades que demandan las formaciones de vuelo satelitales, tanto para la integración de capacidades en comunicaciones como el rango de operación, y la precisión de ajuste entre las constelaciones, como es el caso de sistemas de sensado y potencia integrados y de bajo costo para responder a la demanda de los servicios actuales, con sistemas de comunicación y navegación en micro GPS (Zenick y Kohlhepp, 2001).

Incluso ejemplos de modelos para mantener la formación autónoma de satélites geoestacionarios con dinámica de navegación regional, desarrollada con modelos de aceleración y modelos de empuje (Kumar, 2017).

\section{Formaciones satelitales}

Los sistemas de control en red aplicados a los sistemas satelitales, reúnen configuraciones como las constela- 
ciones y los clústeres, de ahí que han sido referidos a lo largo del análisis, en razón a la necesidad de disponer de múltiples agentes en red que por su reducido tamaño no tienen las capacidades físicas suficientes para incorporar demasiados equipos a bordo y por lo tanto requieren ser interconectados para mantener funciones conjuntas a misiones particulares.

En este sentido, se toman como referencia los diferentes niveles de coordinación para múltiples satélites (figura 25), pasando por la configuración en enjambre, las constelaciones, las formaciones de vuelo, las reconfiguraciones de cada formación y hasta el nivel superior relacionado con la definición de acuerdo o consensos para niveles de control descentralizados de alta precisión y nivel de autonomía de los agentes.

Uno de los ejemplos de formaciones satelitales es generado mediante control por modos deslizantes en sistemas de segundo orden, aplicado a una formación de picosatélites de bajo empuje como sistemas no lineales tipo MIMO (Li, Pan y Kumar, 2010), y otros avances como el sistema de control de actitud (ACS) con tolerancia a fallos para satélites pequeños, usando algoritmos de control adaptativo no lineal basado en el control por modos deslizantes en terminales singulares satelitales (Cao, Chen y Sheng, 2013).
O el planteamiento de tres algoritmos de control por modos deslizantes para optimizar el consumo de potencia en las diferentes configuraciones de vuelo de pequeños satélites para navegación y control libre de colisiones ( Saaj, Bandyopadhyay \& Bandyopadhyay, 2010).

Alternativas adicionales como los algoritmos de planificación de tareas dinámicas cooperativas y distribuidas, para múltiples satélites basados en aprendizaje híbrido multiagente, son opciones de trabajo para los sistemas en red (Wang, Li, Jing, Wang y Chen, 2011)

Incluso el control de retroalimentación de error mínimo por modos deslizantes para evitar colisiones mediante el control de perturbaciones inciertas con linealización de ecuaciones del movimiento de los pequeños satélites (Cao y Chen, 2016).

Otro de los problemas complementarios al de consenso en las formaciones de satélites, son los dispuestos para la distribución de recursos compartidos en red, en particular para constelaciones de CubeSat, dentro de las cuales el concepto de agente es asignado individualmente a cada CubeSat. En esta los recursos pueden quedar dispuestos de forma descentralizada dentro de la red, de acuerdo a la demanda del servicio asignado de cada misión, configurando

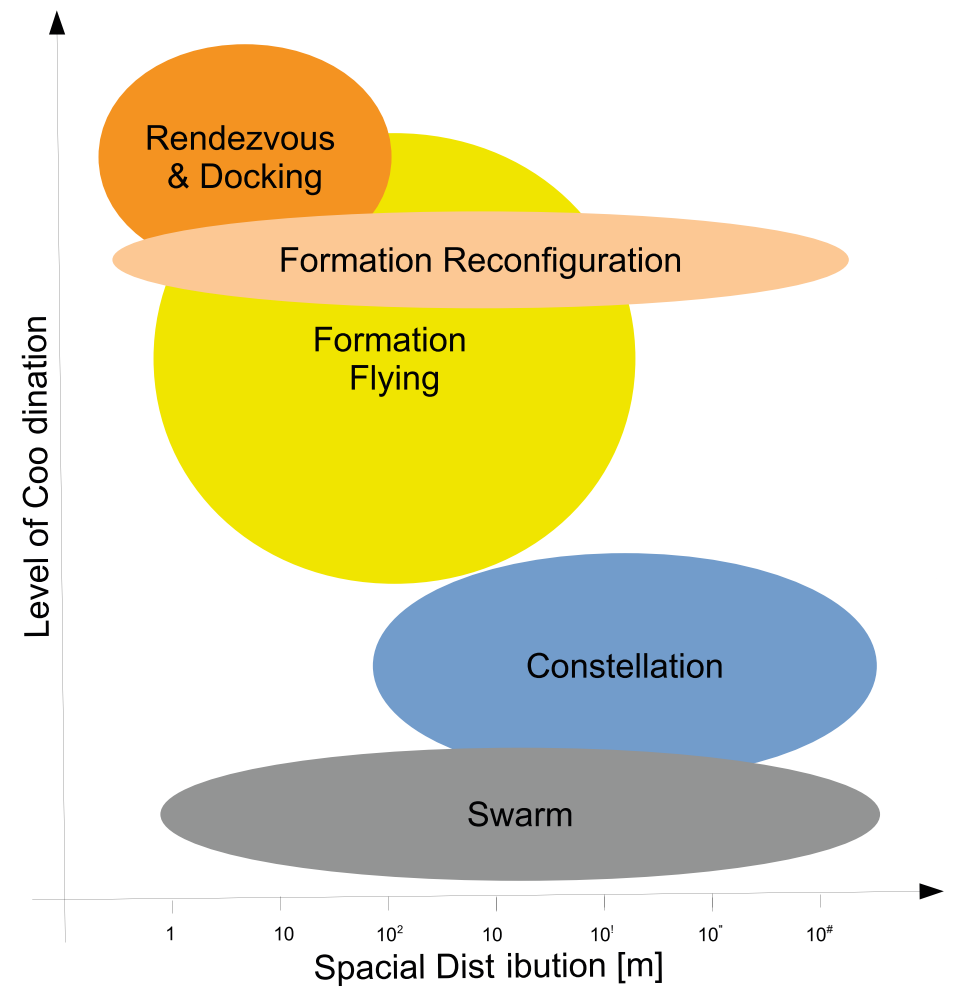

\section{Decentralized Control High level of Autonomy High Precision}

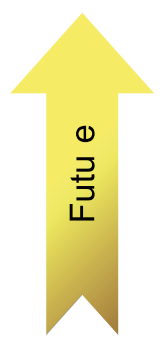
Centralized Control Ground Ops. Low Autonomy Low Precision

Figura 25. Niveles cualitativos de coordinación para múltiples satélites Fuente: Sorensen, 2014, adaptado de Radhakrishnan et al. 
así la disposición de técnicas multiagente como simples algoritmos de asignación manual o el método de agentes evolutivos, (Agogino, HolmesParker y Tuner, 2012).

Sistema de control de órbita y actitud de satélites pequeños (AOCS) (Guerman, Ovchinnikov, Smirnov y Trofimov, 2012), proponen el control de dos satélites en formación, mediante la ecuación lineal de Schweighart-Sedwick, junto con los efectos del factor J2, con el fin de buscar la estabilización de la actitud magnética pasiva y la estabilización del spin, respecto a todas las posiciones y velocidades iniciales correspondientes al hecho de poder mantener el movimiento relativo periódico entre los dos satélites.

Otro desarrollo para mantener la formación de satélites es el uso de un elevador diferencial y el arrastre bajo el efecto J2, dispuesto para una órbita circular cercana LEO, basado en una ley de control por retroalimentación con la función de Lyapunov, con las cuales se controla cada satélite (Shao, Song, Wang, Zhang y Chen, 2017). Además de la determinación de un proceso de control cooperativo mediante ecuaciones de variación de Gauss, para el control de posicionamiento en la órbita dentro de un clúster de satélites, utilizando la dinámica de sistemas multiagente (Zhang y Gurfil, 2016). O la dinámica de interacción de grafos para el control coordinado distribuido con el fin de preservar la conectividad en sistemas multiagente ( $\mathrm{Ji}$, Member, Egerstedt y Member, 2007), buscando aplicar las maniobras rendezvous o encuentro de vehículos espaciales mediante el control de posición y velocidad, así como el análisis de problemas en formación para actuar sobre la dinámica e interacción de grafos, con la adición de pesos en los bordes de los grafos para garantizar así la conectividad de la red.

Otras formas clásicas de control se utilizan también como el control robusto para un sistema lineal y no lineal (Xu, Fitz-coy, Lind y Tatsch, 2007), a través de un diseño de controlador $\mu$ para el vuelo de satélites en formación en una misión nominal de $800 \mathrm{~km}$ de altitud, dentro de una órbita de referencia circular, el cual se caracteriza por brindar un control robusto a las incertidumbres, satisfaciendo los requerimientos de consumo de combustible en misiones no nominales de 0.1 a 7.978 km con órbitas de referencia elípticas, para las cuales se logra mantener la formación con los niveles de velocidad proyectados (43.86 m/s/año) así como con las misiones nominales con (39.65 m/s/año).

Como complemento se logra establecer un comparativo entre el controlador $\mu$, el control por modos deslizantes (SMC) y el regulador cuadrático lineal (LQR) con un controlador robusto no lineal en una formación de satélites (Xu et al., 2007).
Otros algoritmos de control de vuelo de clústeres satelitales, plantean la arquitectura para el ajuste de distancias dinámicas entre cada satélite, incluyendo restricciones y constantes de empuje mínimo para la operación suficiente del propelente requerido para los desplazamientos de cada satélite dentro del clúster, (Mazal y Gurfil, 2014). En este sentido, se complementan aspectos como la planeación de trayectorias colectivas para enjambres en presencia de fuerzas electromagnéticas entre los satélites, logrando con esto la capacidad de maniobra, que de acuerdo a la velocidad y comportamientos entre las interacciones del enjambre, posibilitan la operación hibrida de sistemas y el empuje coordinado dentro del enjambre, (Huang, Yang, Zhu Y Zhang, 2014) sistemas de vuelo en formación para misiones militares y no militares, desde el planteamiento de ecuaciones relativas no lineales, basadas en un modelo de incertidumbre del factor $\mathrm{J} 2$ ligado a los niveles de precisión de sensores para el control de requerimientos en el consumo de combustible de los satélites (Xu et al., 2007).

Por otra parte, se han desarrollado tres enfoques diferentes de control para formaciones de satélites pequeños, considerando la primera en términos de los algoritmos de líder seguidor, la segunda aplicada al enfoque conductual con el cual se direccionan los agentes de acuerdo al comportamiento deseado del promedio ponderado de los satélites (Lawton y Beard, 2002), sin embargo, la matemática aplicada es compleja y un tercer enfoque dado por estructuras virtuales a partir de la cual se trata la formación como un solo cuerpo rígido a ser controlado (Wang, 1996), logrando orientarla a medida que va evolucionando como un todo y manteniendo una geometría rígida entre los múltiples agentes (Beard, 2002), adicional a otras perspectivas donde se toma el líder con un marco referencial rígido también (Ren y Beard, 2004).

Una alternativa deducida de los enfoques anteriores se traduce en la descentralización del sistema, la retroalimentación y las maniobras con arquitecturas como el control de formaciones comparado (Ren y Beard, 2004), entre una arquitectura centralizada basada en el enfoque de estructura virtual y arquitecturas descentralizadas.

De tal manera que se establece una localización instantánea del vector de dirección y coordinación, en cada uno de los satélites de la formación (figura 26), donde se ilustran las posiciones en metros en sus tres ejes coordenados y son sincronizadas las comunicaciones bajo un ancho de banda a través de una topología de anillo bidireccional entre nueve satélites de $150 \mathrm{~kg}$ y uno central de $1.500 \mathrm{~kg}$ aprox. en un diámetro aproximado de trabajo de $1 \mathrm{~km}$ con distancias equivalentes entre los satélites. 


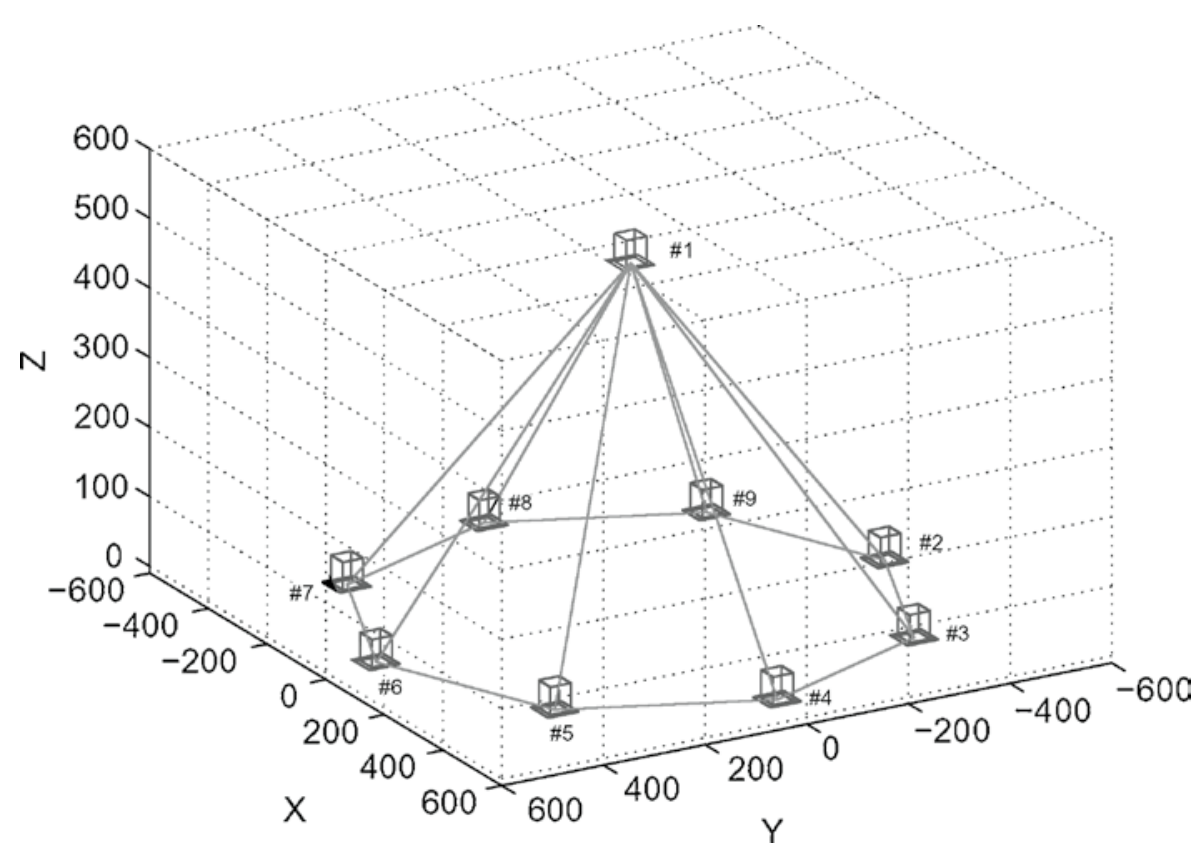

Figura 26. Configuración geométrica de nueve satélites Fuente: Ren y Beard, 2004.

Con esta topología se logra la sincronización y posterior actualización de los estados deseados de cada satélite dentro de la formación con el enfoque de una estructura virtual.

En los últimos avances respecto a los modelos con agentes, se han desarrollado alternativas que incluso son propuestas para ser aplicadas en sistemas multiagente no lineales, como las formaciones de satélites en vuelo, o el caso de protocolos de consenso global no lineal con la estrategia de líder seguidor y con entradas de saturación, obtenidos en modelos de simulación de sistemas industriales con el enfoque de retroalimentación de ganancia alta-baja (Wang, Wang, Zhang y Li, 2016).

En comparación con estas opciones de consenso, se han presentado incluso alternativas para aplicar la inteligencia artificial distribuida (IAD), a los diferentes subsistemas de un satélite tipo CubeSat, con lo cual se formalice el paradigma de agentes de software. Aunque se deja abierta la necesidad de implementar y validar estas propuestas con simulación a modelos de ingeniería de un satélite (Dhios, 2013), retomando principios básicos de la inteligencia artificial para agentes, como los límites de comunicación, le heterogeneidad de los agentes y la dinámica tanto de los ambientes como de los problemas de carga y recursos, previamente estudiados como sistemas multiagente (Lesser, 1995).
Se han generado propuestas para interconexión de satélites pequeños, como es el caso de la optimización por colonia de hormigas (ACO), con la cual se plantea el manejo de sistemas de satélites distribuidos, basada en enjambres inteligentes que se adaptan para intercomunicarse y reconfigurarse dentro de la red requerida (Chen y Zeng, 2013).

Similar a la formulación planteada como modelos formales de protocolos de control en red basado en la generación estocástica de redes Petri, configurando reglas de mapeo y protocolos de patrones para el control de flujo de información entre los satélites (Zhu, Yang, Huang y Lu, 2015).

Una alternativa de los diseños de misión para formaciones es la posibilidad de desarrollar los software de simulación para los agentes en vuelo, como se ilustra en la figura 27, donde se han implementado controles de dirección PD para el esquema de maniobra rendezvous consistente en las maniobras orbitales y de trayectoria para acercar los agentes uno de otro (Sorensen, 2014).

Para reducción de costos en misiones de vuelo en el desempeño de nuevas tecnologías como los satélites pequeños, se planteó el sistema de operaciones en tierra de luces apagadas (LOGOS), y las pruebas del concepto de agentes (ACT), para demostrar la capacidad de autonomía de las misiones de vuelo de dos sistemas en red, como comunidades interconectadas a través de una arquitectura 


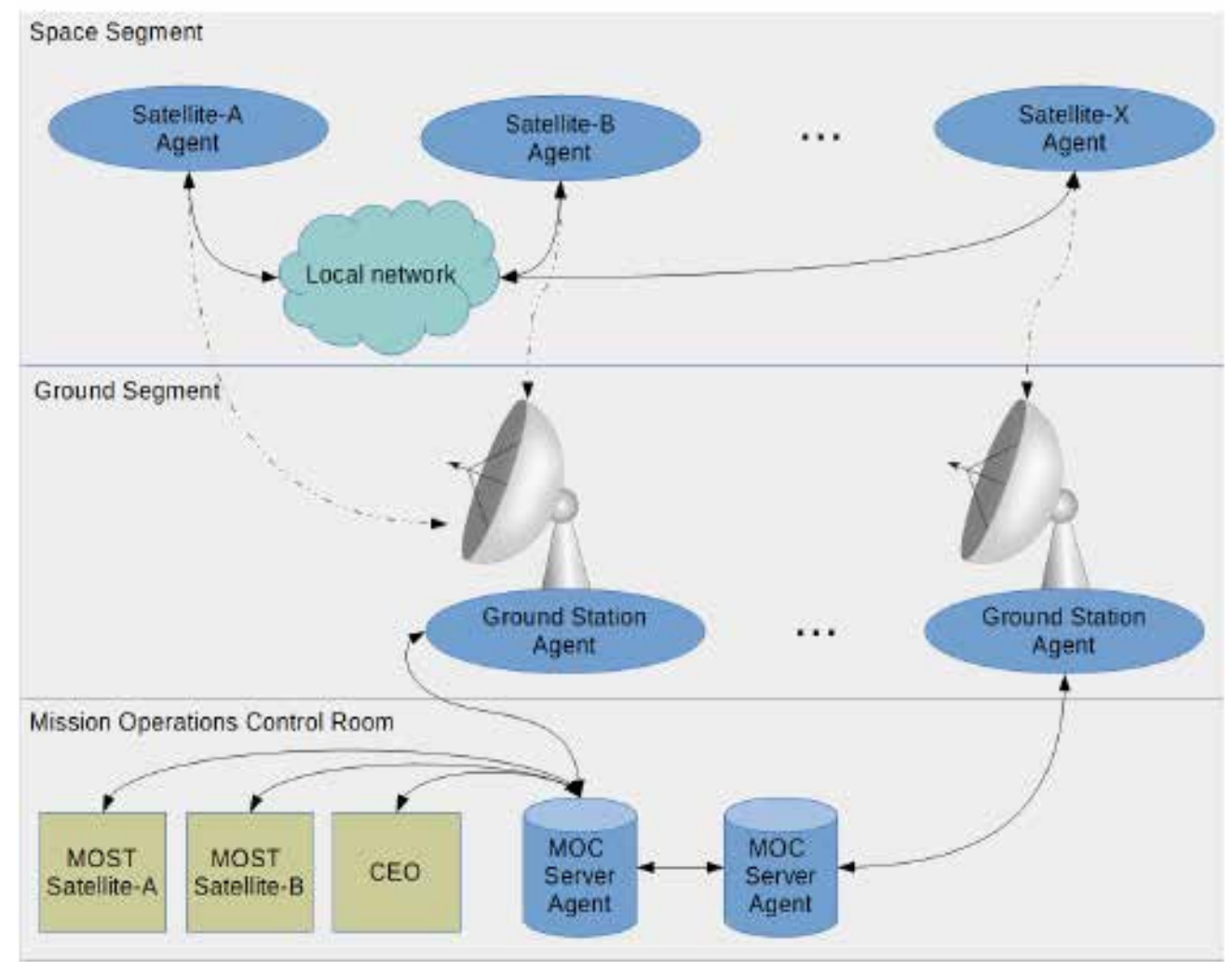

Figura 27. Diagrama de flujo de datos COSMOS Fuente: Sorensen, 2014.

y un software propios para dicha aplicación (Truszkowski, Rash, Rouff y Hinchey, 2004).

\section{Otras aplicaciones de sistemas de control en red}

Algunas tendencias marcadas en términos de los sistemas de control en red se basan en la categorización de las redes, flujos de datos en la red, eficiencia y uso de recursos, para lo cual se implementan estrategias de retroalimentación adaptadas a redes con enlaces de comunicación poco fiables, para poder controlar los acuerdos de los sistemas multiagente entendiendo el comportamiento individual de los agentes frente a su desempeño global o grupal (Zampieri, 2008).

Sistemas de control de complejidad reducidos, donde se presentan controladores de estado finitos que pueden ser aplicados en sistemas robóticos autónomos, para observar el papel de la retroalimentación en la simplificación de trayectorias aplicadas a las reglas básicas de autómatas de estado finito, proponiendo un tipo de controlador de estado finito aleatorio para reducir la complejidad del control (Brockett, 2008).

El problema de consenso en las redes de agentes incluye también las topologías de conmutación y retardos de tiempo, con las cuales se proponen topologías fijas o conmutables para redes directas y topologías fijas con retardo de tiempo y comunicación para redes indirectas, todo esto mediante protocolos de consenso para sistemas multiagente, enlazados con conectividad algebraica y uso de grafos y dígrafos.

De igual modo se plantea la función de Lyapunov como función desagregada para redes dinámicas desagregadas, considerando los problemas de consenso y la dirección del flujo de información desde la teoría de grafos (Olfati y Murray, 2004).

Otras aplicaciones que se han planteado incluyen tecnologías multiagente bioinspiradas para la gestión de recursos corporativos en el modelamiento de diferentes procesos de carga, con soluciones inteligentes integradas y apoyadas vía satélite con comportamientos en tiempo real sobre dispositivos móviles de seguimiento (Tsarev, 2013).

De otro modo, las aplicaciones en términos de organizaciones también han cubierto el concepto de agentes modelando los diferentes módulos de la gestión empresarial como los proveedores, los clientes, entre otros, como agentes dentro del término metamodelos con sus respectivas interacciones (Villaplana, 2008). 
Una mirada diferente para considerar sistemas multiagente es como equipos independientes de un mismo sistema, el cual ha sido también la configuración que se da a los componentes internos de un sistema como agentes independientes, es decir que los subsistemas como la interfaz de comunicaciones, la conexión de red o la unidad de procesamiento central, entre otros, pueden considerarse agentes y a su vez la operación entre estos ser considerada un sistema multiagente (Rouff, 2000).

El desarrollo de sistemas multiagente ha tenido una amplia aplicación en los sistemas informáticos y de computación, a la hora de formular técnicas y herramientas para el desarrollo de software, traducidos en metodologías de diseño y desarrollo de algoritmos, como orientación de objetos, rediseño de arquitecturas de software, entre otras, enfocadas al análisis y diseño de agentes, sus características y métodos de uso, descritos en algoritmos de bajo y alto nivel, como es el caso final de aplicación de los sistemas multiagente en los sistemas informáticos (Julián y Botti, 2003).

De otro modo, el foco de los sistemas multiagente se ha soportado en referentes computacionales que vinculan tanto los principios como los modelos, para la interacción efectiva de agentes semiautónomos, e inteligentes en el logro de sus objetivos, (Lesser, 1999). En contraste con conceptos de trabajo de sistemas multiagente basados en minería de datos para la identificación de patrones y clasificación de imágenes de terreno (De Freitas, Filho, De Moura y Silva, 2016).

Actualmente se están desarrollando alternativas de sistemas multiagente, donde se llevan situaciones de sistemas industriales con el modelamiento de las plantas, en términos de la optimización en tiempo real de la producción, teniendo en cuenta tanto sus diferentes subsistemas como el comportamiento general de la planta industrial, el flujo de información y la cooperación entre cada subsistema, que para el caso particular se aplican los resultados al diseño de una formación de satélites a ser analizada posteriormente (Wang et al., 2016).

\section{Seguridad crítica}

Luego de identificar las diferentes formas de uso de los sistemas de control en red para satélites de pequeña escala, es importante considerar otros elementos fundamentales en su operación, como lo son el cálculo y diseño de orbita, todo lo relacionado con la fusión sensorica y detalles de la carga útil, sistemas de prueba y el enfoque de operaciones hacia la seguridad crítica.

\section{Diseño orbital}

El diseño de órbita es una de las tareas implícitas en el diseño de misión, por medio de la cual se establecen no solo el diseño en el proceso de lanzamiento, sino también los tiempos y cubrimientos que han de tener los satélites sobre un área específica.

En este sentido, se parte de su cálculo para determinar y definir el segmento en tierra, los requerimientos en el segmento de usuario y lógicamente el segmento espacial donde se define la tecnología de los satélites que estarán interconectados y capacidades a bordo de cada uno de ellos como agentes dentro de la red (figura 28), donde se representan las distancias intersatelitales y los puntos de referencia del seguimiento de trayectorias en órbita.

Por otra parte, se deben definir las distancias hacia las estaciones en tierra, los tiempos de cobertura y exposición de sensores y cargas útiles para su aprovechamiento desde tierra, según sean las misiones particulares que cumplan dichos equipos.

En términos prácticos, y para el caso colombiano, se han generado estudios para el diseño de órbita según sean los servicios que se quieran obtener de los satélites (Poveda, 2016).

Sin embargo, se han desarrollado trabajos con alturas por debajo de órbita, pero que buscan suplir servicios sin el uso de equipos satelitales. Como lo muestra la figura 29, se puede observar una propuesta de diseño para vehículos no tripulados que sean capaces de llevar cargas útiles a diferentes altitudes sin plataformas de lanzamiento, y que puedan permanecer en ubicaciones específicas mientras cumplen alguna tarea en particular.

Actualmente, otro caso representativo son los globos de Google (figura 30), mediante los cuales se pretende suplir el servicio de internet de forma complementaria a las redes actuales.

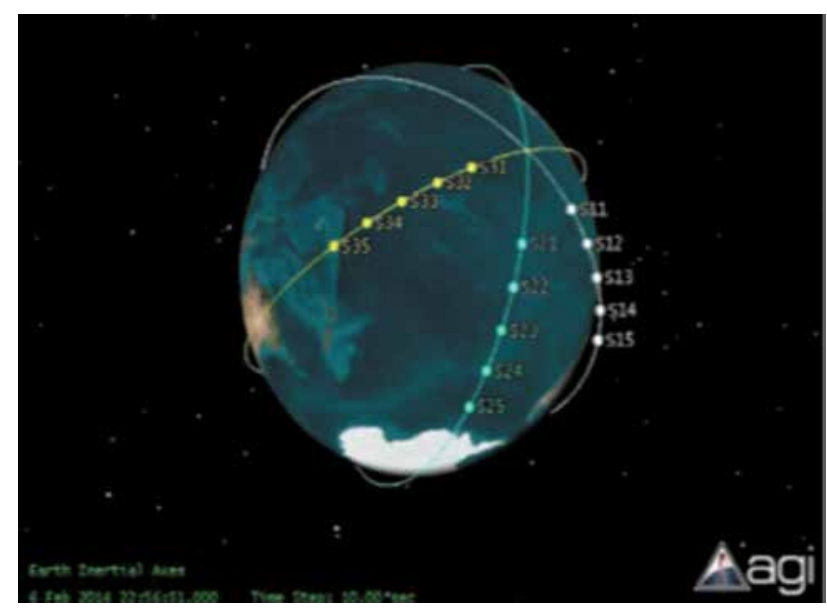

Figura 28. Patrón de vuelo de una constelación en formación Fuente. Radhakrishnan et al., 2016 


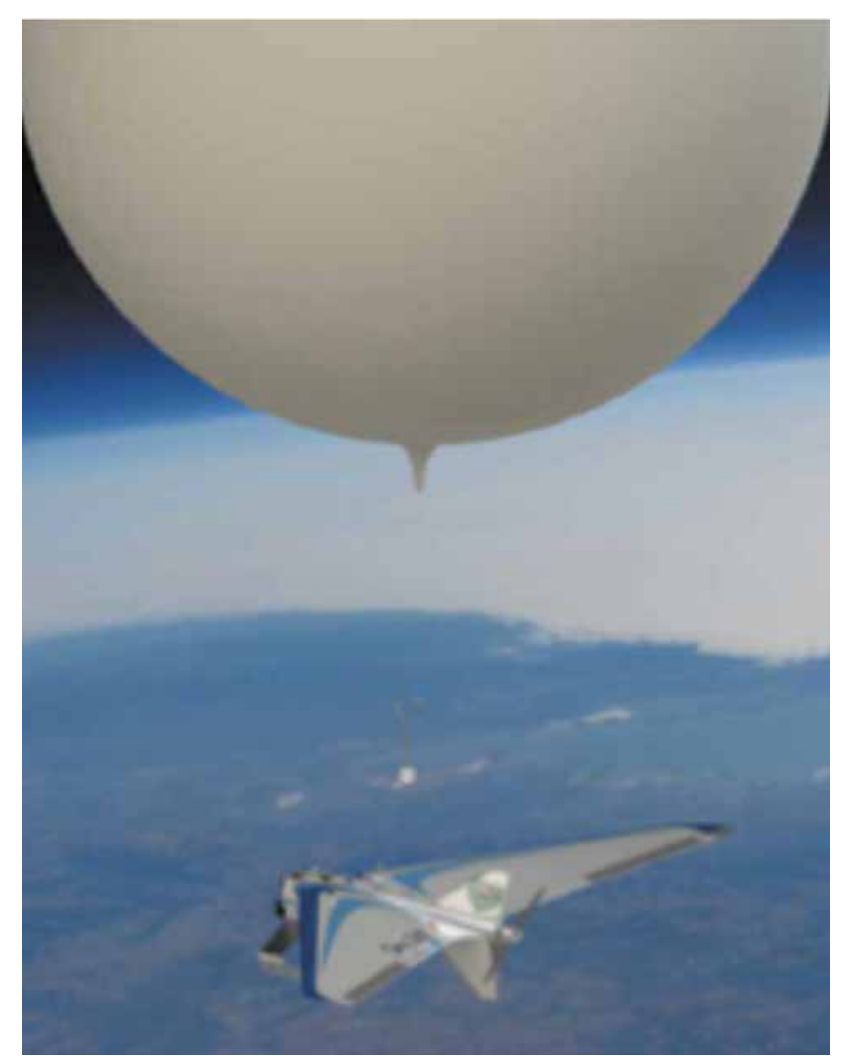

Figura 29. Globo sonda Fuente: Forero y Libertadores, 2015.

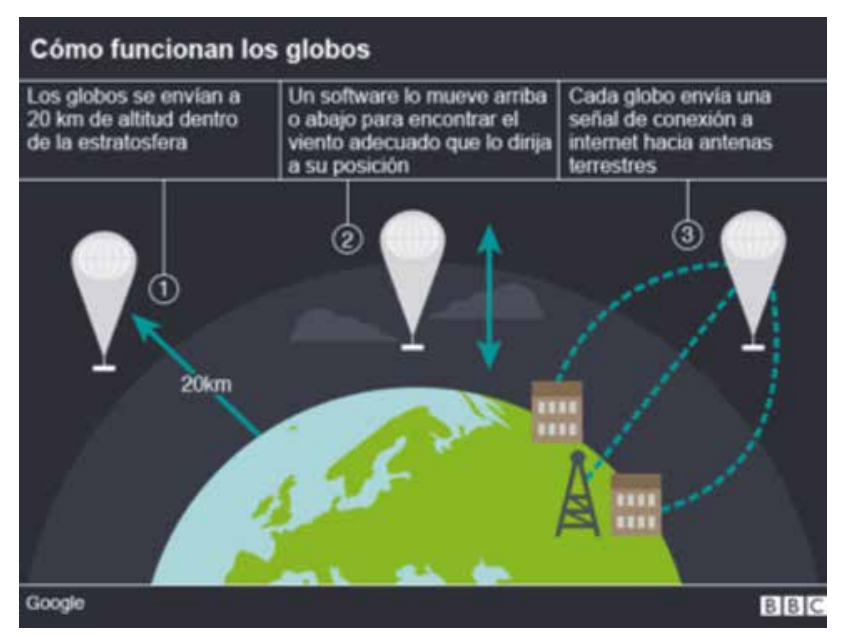

Figura 30. Proyecto Loon Google Fuente: Proyecto Loon Google.

En términos generales, cuando se habla de soluciones satelitales, la tarea en el diseño de órbita es prioritaria y demanda amplios requerimientos de cálculo e integración con todos los sistemas, lo cual implicaría el diseño de misión de la red de agentes.

\section{Fusión sensorica y sistemas de pruebas}

El concepto de fusión sensorica aplicado a los sistemas de control en red, implica la coordinación completa de los sensores a bordo de cada agente como el uso de cámaras multiespectrales (Díaz González, Quintero Torres, Triana Correa \& Morón Hernández, 2014), con las que se espera la obtención de un número representativo de datos.

La fusión sensórica es un aspecto relevante a la hora de establecer los protocolos de trabajo entre sistemas multiagente, en razón a los efectos y ventajas que presentan los sistemas con tecnologías de dispositivos microelectromecánicos (MEMS), desarrollados especialmente para aplicaciones de estructuras pequeñas de bajo costo y de bajo consumo, como es el caso de los satélites de escala reducida.

En este sentido, es importante identificar los protocolos de sincronización y operación de las redes de sensores utilizados sobre las plataformas multiagente, de tal manera que se provean características operaciones de precisión, bajo costo, exactitud y complejidad adecuadas para el soporte de las redes (Sundararaman, Buy y Kshemkalyani, 2005).

Así como la generación de algoritmos escalables de control para redes dinámicas de sensores y fusión sensorica distribuida, mediante sistemas de filtrado y niveles de consenso, diseñados para ajustar los parámetros de medición según un promedio de los diferentes nodos de la red de sensores (Olfati y Shamma, 2005).

Los sistemas a bordo tienen múltiples protocolos de prueba, requeridos para identificar el comportamiento de materiales, estructuras, conectividad, entre otros, como los sistemas de propulsión y bancos de prueba para nanosatélites en tierra (Mier y Lozano, 2017), ilustrado en la figura 31, donde se prueban los sistemas de control y determinación de actitud, propulsión, navegación e incluso campos magnéticos asociados a su operación.

Por otra parte, se han trabajado sistemas de control de actitud para satélites basados en la descentralización de sus componentes, con lo cual se evidencia un sistema control con redundancia en los puntos de falla para el respaldo operacional de las ruedas de reacción (De Arboleya y Moreno, 2012).

Un concepto adicional es el de hardware in the loop (HIL) aplicado al control de formación de vuelo de pequeños satélites para pruebas de diferentes algoritmos de control (Scharnagl et al., 2016), adicional a las pruebas se proyectan las capacidades de propulsión como alternativas de consumo de potencia para los clústeres de nanosatélites, dispuestos en sistemas de propulsión eléctrica miniaturizada (EP) para mantener las capacidades de orbita requeri- 


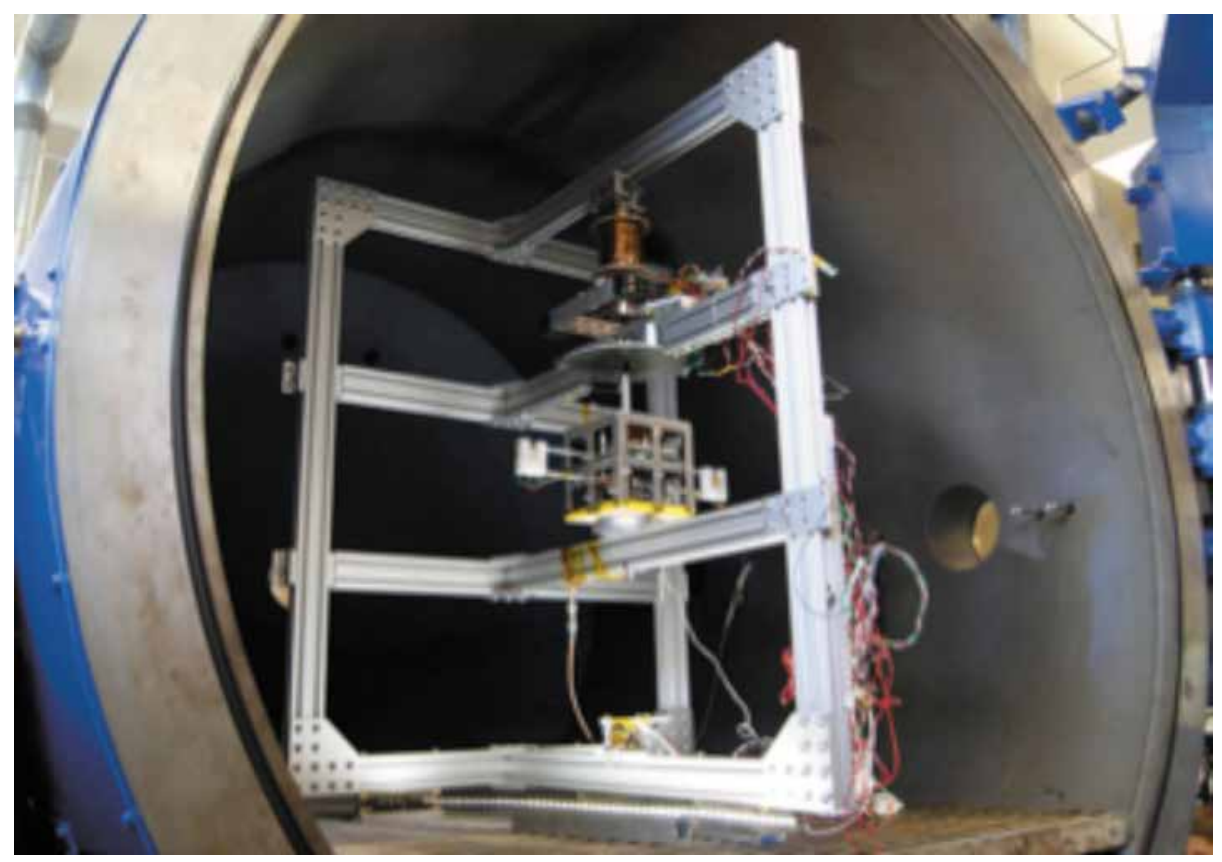

Figura 31. Sistema de pruebas CubeSat

Fuente: Mier y Lozano, 2017.

das, todo mediante un controlador de empuje cíclico para cada nanosatelite (Edlerman \& Kronhaus, 2016).

\section{Seguridad crítica}

En los nuevos problemas operacionales y de acuerdo a los escenarios de aplicación de sistemas militares, se traen a colación interacciones centralizadas y descentralizadas que demandan la coordinación de acciones en conectividad y comunicaciones, que requieren vuelos en formación, clasificación y ataques cooperativos y supervivencia, hasta combinación de múltiples sistemas (Murray, 2007).

Como se ilustra en la figura 32, además de otras aplicaciones como redes de sensores móviles, sistemas de transporte con autopistas inteligentes, control de tráfico aéreo, sistemas coordinados de UAV, entre otros.

Un aspecto relevante frente a la disposición de agentes en la seguridad crítica, es la necesidad de interacción entre tipos de emergencias de gran escala que son tratadas mediante la simulación basada en agentes, logrando la evaluación de impactos desde efectos locales hasta catastróficos, incluyendo tipologías de reacción en diferentes tipos de terrenos o cartografías que son determinadas por la movilidad y capacidad de respuesta de los agentes vinculados según sea clasificada el nivel de impacto y las interacciones requeridas para la generación de respuestas óptimas, gene- ralizadas o específicas en la reacción a los eventos y estructuras modeladas (Hawe, Coates, Wilson y Crouch, 2012).

Dentro de la seguridad crítica también se encuentra el uso de equipos UAV, que soporten la toma de imágenes y video, frente a una situación de riesgo en operaciones de combate donde el apoyo satelital y la red de equipos complementan las misiones con información visual crítica (Skinnemoen, 2014).

En el concepto de seguridad crítica también se aplican modelos como el control de riesgo adaptativo y mecanismos de gestión de la seguridad (ARCSM), para garantizar la minimización del riesgo cuanto sea posible, tomando para esto el control por retroalimentación con algoritmos adaptativos desarrollados para cada nodo, logrando así el monitoreo permanente de estos con una arquitectura de control retroalimentada y distribuida (Jiang, Sang y Zhang, 2012) there are some growing critical challenges of security management and risk control. For the unpredicted and especially unsecured environments, such security-critical distributed real-time embedded systems need to enforce security on multiple nodes in order to against the potential threats as well as satisfying the real-time requirements. Unlike the traditional ad hoc static 


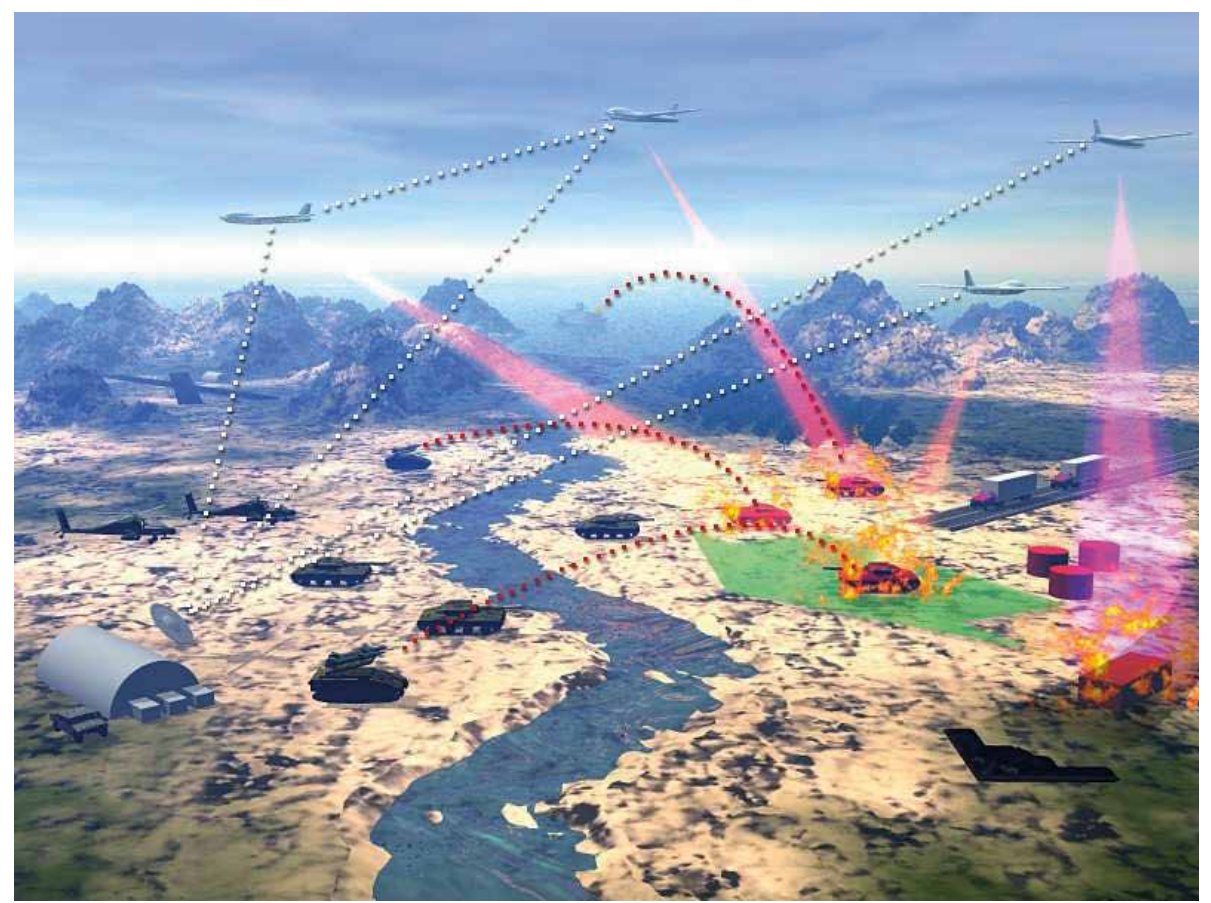

Figura 32. Ilustración de un comando y control distribuido Fuente: DARPA, Murray, 2016.

designing approaches, based on feedback theory, this paper proposes an Adaptive Risk Control and Security Management (ARCSM).

En términos de defensa satelital se ha diseñado un sistema de razonamiento autónomo multiagente (MAARS), con el cual se planean escenarios de riesgo frente a ataques sobre los satélites y se generan estrategias de control con modelos de incertidumbre, para la toma de decisiones por parte de los agentes, (Kwak, Scerri, Tambe, Sert y Freedy, 2011).

\section{Tecnologías comparadas}

Los sistemas de control en red han tenido amplios enfoques, donde se incluye el concepto de interacción entre agentes (González, 2012), en aplicaciones de la robótica cooperativa como las relacionadas a continuación:

- $\quad$ Simulación de juegos.

- Búsqueda y rescate.

- Cubrimiento de regiones o exploración de terrenos desconocidos y hostiles.

- Simulación de sistemas biológicos.

- Cardúmenes de peces.

- Aves.

- Colonias de hormigas.

- Ecosistemas de presas y cazadores.
- Enjambres.

- Formaciones y coreografías.

Entre otros usos, como redes de energía, sistemas sociales, redes financieras, sistemas complejos y demás formas de interacción entre agentes, de donde se pueden buscar soluciones aplicables a los sistemas satelitales.

\section{Aplicaciones en robótica móvil}

Estados del arte relacionados con la robótica, reúnen múltiples conceptos por medio de los cuales se abordan las necesidades de estudio en sistemas en red, como lo son; sistemas multirobot divididos en arquitecturas, comunicaciones y redes de sensores, inteligencia y robótica de enjambres y sistemas cooperativos, como lo muestran Zhu y Yang (2010), donde se concreta el interés de estudio en redes de sensores y enjambres robóticos.

En robótica cooperativa se han aplicado los principios de sistemas en red, como en el caso de lograr determinar algoritmos de consenso para control cooperativo multivehículo (Ren, Chao, Member, Bourgeous y Member, 2008), con el cual se validan los movimientos y desplazamientos de robots dentro de un área específica y con múltiples parámetros de control.

Como la aplicación de algoritmos de consenso distribuido con maniobras rendezvous o la aplicación de alineación de ejes. Que desde sus inicios consideraban la 
tolerancia de fallos, la confiabilidad del sistema y la cooperación debida a situaciones de competitividad entre robots móviles (Cao, Fukunaga, Kahng y Meng, 1997).

Se ha trabajado en la dinámica de sistemas distribuidos para múltiples vehículos en red, analizando el comportamiento colectivo de los grupos desde el punto de vista de las interacciones locales que se puedan presentar, es decir mediante la aproximación a sistemas de administración de recursos computacionales embebidos en múltiples vehículos, con el fin de subsanar operaciones de búsqueda y rescate, sistemas de reconocimiento, supervivencia, combate, entre otros, como lo describen tácitamente Wei, Randal y Beard (2007).

Otro caso de aplicación de la teoría redezvous se muestra en el control de tiempos y sincronización de tareas realizado en un ejemplo de misiones con múltiples UAV, considerando las capacidades para llegar a un objetivo de manera simultánea, para lo cual se desarrolla la gestión de punto de encuentro redezvous a través del diseño de máquina de estados y un control cooperativo con enfoque de descomposición aplicado a requerimientos de sistemas de vehículos múltiples (Mclainl, Chandler, Rasmussen y Pachter, 2001).

De manera complementaria se han realizado amplios trabajos en materia de sistemas multiagente con aplicaciones en detección de objetos, habilidades básicas de movimiento, configuraciones multicapa, aprendizajes multiagente, manejo de acciones, control de movimiento y control de colisiones, explícitos en la dinámica del futbol de robots (Ortega, 2006).

Los sistemas de múltiples UAV aplican también algoritmos de control de caza, tales como la búsqueda de objetivos, mediante intercambio de información de sensores en ambientes desconocidos con algoritmos de aprendizaje en línea, para la cooperación y coordinación en regiones subdivididas según el número de UAV.

Alianzas dinámicas con algoritmos de asignación de tareas de control inteligente de presa y cazador, con coordinación y banderas de estado, seguimiento con modelos geométricos determinados por método gráfico o método de espacio libre, seguimiento con campos potenciales artificiales y el gradiente de dirección, persecución basada en inteligencia artificial como redes neuronales, algoritmos genéticos, lógica difusa, algoritmos evolutivos, entre otros, y de manera complementaria algoritmos para captura de objetivos basada en predicción dinámica de presa y cazador (Xiang y Daqi, 2013).

En los sistemas de control cooperativos se describe también el modelo Kripke, respecto al análisis de máquinas de estado finito, utilizado para el control y monitoreo de ruta de múltiples UAV, aplicando el árbol de lógica computacional (CTL), con la exploración exhaustiva del espacio de estados y del comportamiento del sistema, para definir tanto número de equipos en vuelo como condiciones y selección de ruta para estos (Sirigineedi, Tsourdos, White y Zbikowski, 2011)

Se tienen aplicaciones con UAV donde el mapeo de territorios hostiles, las operaciones de supervivencia y rescate y los retardos en las comunicaciones, son capacidades desarrolladas para la inclusión del control distribuido ante estrategias de comunicación y redes con sistemas de navegación y visión en tiempo real, mediante la inclusión de arquitecturas como el control de iniciativa mixta para equipos de autómatas, (MICA), con la cual se integran soluciones para UAV con determinación de ambientes desconocidos, jerarquías, tareas modulares y adaptaciones a sensores y estrategias de misión diversas (Ryan, Zennaro, Howell, Sengupta y Hedrick, 2004).

Una de las configuraciones complementarias que enlaza la robótica con el control de sistemas en red satelital, es el control remoto de robots, mediante el sostenimiento de la órbita de una formación de satélites pequeños, con la cual se mantiene la distancia y proyección de comunicaciones entre satélites con línea de cobertura hacia los robots en la superficie de la tierra (Padron, Nebylov y Knyazhsky, 2017), siendo así una aplicación de integración de uso de redes satelitales con redes terrestres activas.

Se han desarrollado algunos algoritmos de consenso medio para control distribuido, con el fin de mantener el consenso promedio preservando la privacidad de la red, mediante algoritmos de consenso con la derivada de la covarianza y caracterización de la convergencia del sistema, para no dejar información fuera de la red (Mo y Murray, 2017), todos estos aplicados a control de sistemas multiagente.

En términos de consensos promedio, se han desarrollado sistemas multiagente neuronales en redes no dirigidas con ajuste y conmutación de topología para la estabilización en términos de los eigenvalores del Laplaciano, junto con el método de desigualdad de la matriz lineal del sistema (Sun, 2012).

Un algoritmo de consenso para formación en vuelo con control líder seguidor, planteado mediante modelos con dinámica de segundo orden, manteniendo un flujo de información unidireccional, incluso en caso de no presentarse liderazgo centralizado de la red, aplicando ajustes al algoritmo para abordar problemas previo a la identificación clara de los estados (Ren, 2006). Adicional a esto se han planteado modelos de control conductual para formaciones de robots con topologías de anillo (Lawton, 1999). 


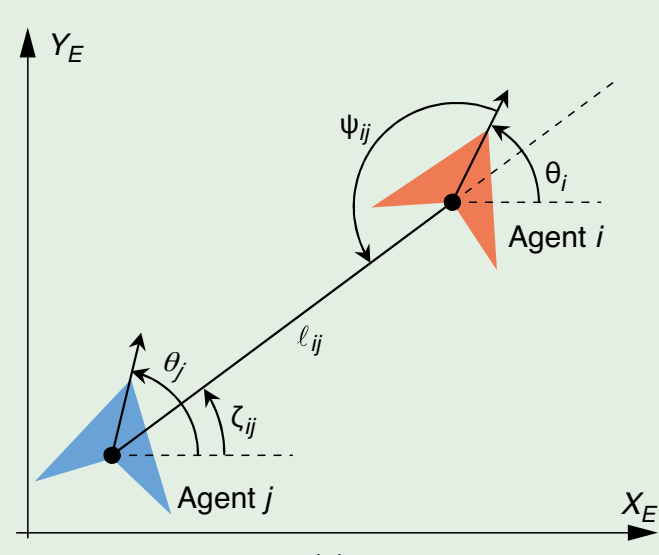

(a)

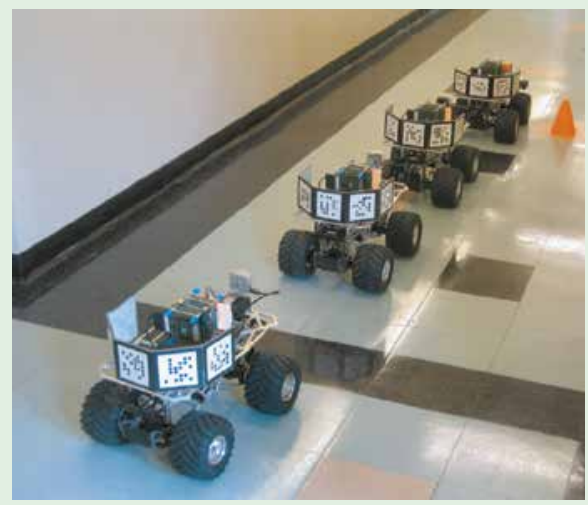

(b)

Figura 33. Experimento de líder seguidor en agentes Fuente: Cruz et al., 2007.

En la figura 33, se muestra la aplicación del control cooperativo descentralizado en el aprovechamiento de los sistemas embebidos junto con las redes de sensores en robots móviles, a través de una plataforma de pruebas de sistemas multivehículos (COMET), con implementación de control PID y simulación con GAZEBO (Cruz et al., 2007).

Otro trabajo complementario es el modelamiento y configuración de robots móviles para el análisis de topologías controladas según la posición de los móviles y la velocidad resultante luego de la conmutación de red en anillo, estrella y cadena, como lo muestra la figura 34, refiriendo cada robot como una masa puntual y donde todo lo anterior es realizado bajo una estrategia de control distribuido con formaciones homogéneas (Martínez, 2015).
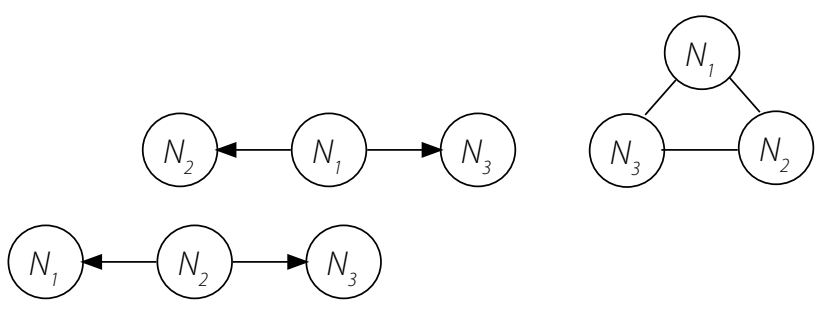

Figura 34. Topologías de red estrella, anillo en formación y cadena Fuente: Martínez, 2015.

Con estas configuraciones fue necesario formular cada eje de los robots por separado, con lo cual resultan leyes de control para cada eje, sin embargo, los resultados dan el paso a inclusiones de nuevas trayectorias y nuevas topologías para trabajos posteriores, en caso de diseñar el sistema para evitar colisiones (Martínez, 2015).

Dentro de las propuestas de trabajo de sistemas relacionados con el desarrollo de la fusión sensórica, se tienen avances en la implementación de filtros de consenso para redes de sensores y distribución operativa de la fusión sensórica (Ögren, Fiorelli, Leonard y Member, 2004), así como el desarrollo de redes distribuidas de sensores aplicadas a control cooperativo en escenarios de comunicación y redes de múltiples vehículos aéreos, para la defensa en operaciones marítimas, considerando la disposición de nodos de retardo múltiples y el diseño de controladores de autoajuste extremo, en redes de sensores distribuidos y conectados de forma inalámbrica (Richard, 2009).

La disposición de sistemas en enjambre de robots, vincula el diseño de arquitectura, la formalización de redes de sensores y comunicaciones, disponiendo de enjambres inteligentes y cooperación entre los robots de la red, basados en la aplicación del filtro de Kafman, extendido con un estimador de estados o sistemas para la localización de nodos en redes de sensores con tolerancia de retardos funcionales (Zhu y Yang, 2010), por otra parte, se proponen sistemas de optimización de partículas en enjambre, basados en los estados de la vecindad o funciones de neuronas virtuales con componentes de percepción, comunicador, reflector y reconocimiento en las redes homologas a los sistemas biológicos.

Se han desarrollado técnicas de control bioinspiradas, como la optimización de las colonias de hormigas, con las cuales se formulan los grafos característicos, incluyendo estocástica y modificaciones de datos dinámicas en múltiples objetivos (Dorigo, Birattari y Stutzle, 2006).

Recientemente el concepto de optimización aplicado al control de estructuras en red, se identifica con el uso de algoritmos para optimización adaptativa distribuida, con la cual se evalúan los pesos y restricciones de la red, mediante la teoría de grafos y posteriormente se hace la esti- 
mación del gradiente como base al consenso distribuido de la red (Kempton, Herrmann y Di Bernardo, 2016), por otra parte, estas investigaciones han trascendido a la estimación de eigenvalores del laplaciano del grafo, utilizado ahora para la configuración de consenso robusto a través de estrategias multicapa adaptativas, (Kempton, Herrmann y Di Bernardo, 2017).

\section{Conclusiones}

La revisión y búsqueda de antecedentes del concepto de sistemas de control en red como base para la configuración y diseño de misión de sistemas satelitales de pequeña escala, se logró sintetizar mediante la descripción de los diferentes tópicos y descriptores con los que se estructura la revisión documental, alcanzando con esto la identificación y muestra de los factores de análisis, con los que se ilustran diferentes escenarios de trabajo para la generación de soluciones a sistemas satelitales alternativos al uso de satélites de gran escala.

A través del análisis de los factores de diseño de misión, carga útil, operación, configuración, control, pruebas y emulación de sistemas, se ilustraron diferentes escenarios de trabajo básicos para el desarrollo de sistemas de control en red, con el fin de ser dispuestos para ser aplicados a modelos de integración de tecnologías y desarrollo de capacidades en la prestación de servicios aeroespaciales.

Se identificaron las necesidades y referentes de interés, tanto de países líderes en el sector espacial, como países en vía de desarrollo, para el diseño de estrategias de bajo costo y de configuración de sistemas multiagente, mediante la descripción de experiencias y requerimientos de uso en diferentes tipos de proyectos de equipos de pequeña escala, así como de modelos aplicados en robótica móvil y en particular sobre plataformas de sistemas de aeronaves no tripuladas.

Se recopilaron los requerimientos logísticos, operativos y se describieron las tendencias en las investigaciones y producción de empresas de los gestores de servicios aeroespaciales, para cada una de las estructuras y componentes de la arquitectura genérica de las plataformas satelitales, con las que se presentaron los mecanismos de prueba, los sistemas de la fusión sensórica y el concepto de diseño de misión, como eje articulador de los propósitos espaciales.

De igual modo, se presentaron diferentes modos de configuración para el control de actitud, distribución de recursos en red, así como diferentes tendencias en la programación de redes basadas en agentes, pasando por algoritmos adaptativos y robustos de la robótica móvil hasta configuraciones de inteligencia artificial distribuida como apoyo a la administración de recursos en red.
En términos generales, el requerimiento de configuración de satélites de pequeña escala mediante sistemas de control en red, está apoyado de procesos para la definición de requisitos de misión como primera medida, diseño de orbita, diseño de sensores a bordo, sistemas de propulsión, métodos de consenso, algoritmos para el seguimiento de trayectorias y definición de formaciones para la cooperación de recursos en red.

Finalmente se dejan abiertas las posibilidades para el uso de los factores de análisis, a fin de abordar propuestas de operación de sistemas satelitales multiagente, que sirvan como medio para el ejercicio de la defensa y la soberanía en el uso del espacio con soluciones de bajo costo que implican sistemas de control en red, y que demandan nuevas configuraciones por la limitada capacidad de recursos de los satélites de pequeña escala.

\section{Referencias}

Abbott, M. (2000). The Role of Small Satellites in NASA and NOAA Earth Observation Programs, 41-50. https://doi.org/10.17226/9819

Agogino, A., HolmesParker, C. \& Tuner, K. (2012). Evolving distributed resource sharing for cubesat constellations. GECCO'12 - Proceedings of the 14th International Conference on Genetic and Evolutionary Computation, 1015-1022. https://doi. org/10.1145/2330163.2330305

Alvarez, J., \&Walls, B. (2016). Constellations, Clusters, and Communication Technology: Expanding Small Satellite Access to Space.

Beard, R. W. (2002). Virtual structure based spacecraft formation control with formation feedback. AlAA Guidance, Navigation, and Control Conference and Exhibit, 1-8. Recuperado de https://pdfs.semanticscholar.org/3946/b500ad05a2d9f6c0a9519054e0b7c82e9f77.pdf

Bouwmeester, J., \& Guo, J. (2010). Survey of worldwide pico- and nanosatellite missions, distributions and subsystem technology. Acta Astronautica, 67(7-8), 854-862. https://doi. org/10.1016/j.actaastro.2010.06.004

Braukhane, A., Arza, M., Bacher, M., Calaprice, M., Fiedler, H., Koehne, V., ... Rivera, J. J. (2010). FormSat, a scalable formation flying communication satellite system. IEEE Aerospace Conference Proceedings, (1). https://doi.org/10.1109/AERO.2010.5446999

Brockett, R. W. (2008). Reduced Complexity Control Systems?? IFAC Proceedings Volumes (Vol. 41). IFAC. https://doi. org/10.3182/20080706-5-KR-1001.00001

Cao, L., \& Chen, X. (2016). Minimum sliding mode error feedback control for inner-formation satellite system with $\mathrm{J} 2$ and small eccentricity, 59(July), 1-18. https://doi.org/10.1007/s11432016-5573-1

Cao, L., Chen, X., \& Sheng, T. (2013). Fault tolerant small satellite attitude control using adaptive non-singular terminal sli- 
CIENCIA Y PODER AÉREO | ISSN 1909-7050 | E-ISSN 2389-9468 | Vol. 13 | Núm. 2 | Jul - Dic 2018 | Escuela de Postgrados de la Fuerza Aérea Colombiana | pp 90-125

ding mode. Advances in Space Research, 51(12), 2374-2393. https://doi.org/10.1016/j.asr.2013.02.004

Cao, Y. U., Fukunaga, A. S., Kahng, A. B., \& Meng, F. (1997). Cooperative mobile robotics: antecedents and directions. Proceedings 1995 IEEE/RSJ International Conference on Intelligent Robots and Systems. Human Robot Interaction and Cooperative Robots, 1, 226-234. https://doi.org/10.1109/IROS.1995.525801

Castellanos, C. A. y Aparicio, L. E. (2014). Diseño y Simulación de un Sistema de Determinación de Actitud basado en el Filtro Extendido de Kalman para el Cubesat Colombia I. Rev. Fac. Ing. Univ. Antioquia, 70, 146-154

Chen, B., Linz, D. D., \& Cheng, H. H. (2008). XML-based agent communication, migration and computation in mobile agent systems, 81, 1364-1376. https://doi.org/10.1016/j. jss.2007.10.026

Chen, Z., \& Zeng, Y. (2013). A Swarm Intelligence Networking Framework for Small Satellite Systems. Communications and Network, 5(September), 171-175.

Cruz, D., Mcclintock, J., Perteet, B., Orqueda, O. A. A., Cao, Y., \& Fierro, R. (2007). Decentralized cooperative control. IEEE Control Systems Magazine, (June), 58-78.

De Arboleya, J. L. G., \& Moreno, J. S. (2012). Multiagent attitude control system for satellites based in momentum wheels and event-driven synchronization. Journal of the Astronautical Sciences, 59(4), 726-746. https://doi.org/10.1007/s40295014-0010-4

De Freitas, N. C. A., Filho, P. P. R., De Moura, C. D. G., \& Silva, M. P. S. (2016). AgentGeo: Multi-Agent System of Satellite Images Mining. IEEE Latin America Transactions, 14(3), 1343-1351. https://doi.org/10.1109/TLA.2016.7459619

Dhios, R. A. (2013). Paradigma de "Agentes de Software" aplicado al desarrollo de satélites amateurs., 1-5. VII Congreso Argentino de Tecnología Espacial. Mayo 15-17, 2013. Mendoza, Argentina.

Díaz González, F. A., Quintero Torres, S. V., Triana Correa, J. S. \& Morón Hernández. D. C. (2014). Aproximación a los sistemas de percepción remota en satélites pequeños.

Dorigo, M., Birattari, M., \& Stutzle, T. (2006). Ant colony optimization. IEEE Computational Intelligence Magazine, 1(4), 28-39. https://doi.org/10.1109/MCl.2006.329691

Edlerman, E., \& Kronhaus, I. (2016). Analysis of electric propulsion capabilities in establishment and. March 2016, Conference: 6th International Conference on Astrodynamics Tools and Techniques, https://www.researchgate.net/publication/304800017_

Engelen, S. (2016). Swarm Satellites: Design, Characteristics and Applications. TU Delft University (Vol. 91). Doi: 10.4233/ uuid:a5dbc5f7-039b-431b-8f32-d3394e690348, https://repository.tudelft.nl/islandora/object/uuid:a5dbc5f7-039b-431b8f32-d3394e690348?collection=research
Forero, D. R., \& Libertadores, F. U. L. (2015). aerodinámica de un globo sonda recuperable y reutilizable 1.

Gill, E., Sundaramoorthy, P., Bouwmeester, J., Zandbergen, B., \& Reinhard, R. (2013). Acta Astronautica Formation flying within a constellation of nano-satellites : The QB50 mission. Acta Astronautica, 82(1), 110-117. https://doi.org/10.1016/j.actaastro.2012.04.029

Guerman, A., Ovchinnikov, M., Smirnov, G., \& Trofimov, S. (2012). Closed Relative Trajectories for Formation Flying with SingleInput Control, 2012. https://doi.org/10.1155/2012/967248

Gurfil, P., Herscovitz, J., \& Pariente, M. (2014). SSC12-VII-2 The SAMSON Project - Cluster Flight and Geolocation with Three Autonomous Nano-satellites.

Hawe, G. I., Coates, G., Wilson, D. T., \& Crouch, R. S. (2012). AgentBased Simulation for Large-Scale Emergency Response: A Survey of Usage and Implementation, 45(1). https://doi. org/10.1145/2379776.2379784

Huang, H., Yang, L., Zhu, Y., \& Zhang, Y. (2014). Acta Astronautica Collective trajectory planning for satellite swarm using intersatellite electromagnetic force. Acta Astronautica, 104(1), 220-230. https://doi.org/10.1016/j.actaastro.2014.07.032

Jadbabaie, A., Lin, J., \& Morse, A. S. (2003). Coordination of Groups of Mobile Autonomous Agents Using Nearest Neighbor Rules, 48(6), 988-1001.

Ji, M., Member, S., Egerstedt, M., \& Member, S. (2007). Distributed Coordination Control of Multiagent Systems While Preserving Connectedness, 23(4), 693-703.

Julián, V., \& Botti, V. (2003). Estudio de métodos de desarrollo de sistemas multiagente. Inteligencia Artificial. Revista Iberoamericana de Inteligencia Artificial, 7(18), 65-80. Recuperado de http://www.redalyc.org/articulo.oa?id=92501806

Kempton, L. C., Herrmann, G., \& di Bernardo, M. (2017). Distributed optimisation and control of graph Laplacian eigenvalues for robust consensus via an adaptive multilayer strategy. International Journal of Robust and Nonlinear Control, 1-9. https:// doi.org/10.1002/rnc.3808

Kempton, L., Herrmann, G., \& di Bernardo, M. (2016). Distributed adaptive optimization and control of network structures. 2016 IEEE 55th Conference on Decision and Control (CDC), (Cdc), 5839-5844. https://doi.org/10.1109/CDC.2016.7799167

Kong, E. M. C., Kwon, D. W., Schweighart, S. A., Elias, L. M., Sedwick, R. J., Miller, D. W., \& Case, T. (2004). Electromagnetic Formation Flight for Multisatellite Arrays, 41(4).

Kumar, V. (2017). Autonomous Formation Keeping of Geostationary Satellites with Regional Navigation Satellites and Dynamics. Journal of Guidance, Control, and Dynamics, 1-21. https://doi.org/10.2514/1.G001652

Kwak, J., Scerri, P., Tambe, M., Sert, O., \& Freedy, A. (2011). Towards a Robust MultiAgent Autonomous Reasoning System (MA- 
ARS): An Initial Simulation Study for Satellite Defense. AIAA Infotech at Aerospace, (March), 1-17.

J.R.T. Lawton \& B.J. Young. (1999). Decentralized approach to elementary formation maneuvers. http://www.et.byu. edu/ beard/papers/library/lawton-tra99.pdf

Lawton, J. R., \& Beard, R. W. (2002). Synchronized multiple spacecraft rotations, 38, 1359-1364.

Lesser, V. R. (1995). Systems : An Emerging Subdiscipline of Al, 27(3).

Lesser, V. R. (1999). Cooperative multiagent systems: a personal view of the state of the art. IEEE Transactions on Knowledge and Data Engineering, 11(1), 133-142. https://doi. org/10.1109/69.755622

Li, J., Pan, Y., \& Kumar, K. D. (2010). Formation Flying Control of Small Satellites, (August), 1-25. https://doi.org/10.2514/6.20108296

Lowe, C. J., \& Macdonald, M. (2014). Acta Astronautica Rapid model-based inter-disciplinary design of a CubeSat mission. Acta Astronautica, 105(1), 321-332. https://doi.org/10.1016/j. actaastro.2014.10.002

Ma, Y., Jiang, W., Sang, N., \& Zhang, X. (2012). ARCSM: A distributed feedback control mechanism for security-critical real-time system. Proceedings of the 2012 10th IEEE International Symposium on Parallel and Distributed Processing with Applications, ISPA 2012, (2), 379-386. https://doi.org/10.1109/ISPA.2012.56

Martin, M., Klupar, P., Kilberg, S. \& Winter, J. (1997). TechSat 21 and revolutionizing space missions using microsatellites. American Institute of Aeronautics and Astronautics. 1-10. https:// digitalcommons.usu.edu/smallsat/2001/All2001/3/

Martinez, R. (2015). Diseño de un controlador para la formación de grupos de robots móviles, Conference: XVI Congreso Latinoamericano de Control Automático, CLCA At: Cancún, Quintana Roo, México, https://www.researchgate.net/publication/280946697.

Mazal, L., \& Gurfil, P. (2014). Acta Astronautica Closed-loop distance-keeping for long-term satellite cluster flight. Acta Astronautica, 94(1), 73-82. https://doi.org/10.1016/j.actaastro.2013.08.002

Mclainl, T. W., Chandler, P. R., Rasmussen, S., \& Pachter, M. (2001). Cooperative Control of UAV Rendezvous.

Medina, C. (2017). Nanosatélites.

Mier-hicks, F., \& Lozano, P. C. (2017). Spacecraft Charging and Attitude Control Characterization of Electrospray Thrusters on a Magnetically Levitated Testbed, (February).

Mo, Y., \& Murray, R. M. (2017). Privacy Preserving Average Consensus, 62(2), 753-765.

Moradi, M. H., Razini, S., \& Hosseinian, S. M. (2016). State of art of multiagent systems in power engineering: A review. Renewable and Sustainable Energy Reviews, 58, 814-824. https:// doi.org/10.1016/j.rser.2015.12.339
Murray, R. M. (2007). Recent Research in Cooperative Control of Multivehicle Systems. Journal of Dynamic Systems, Measurement, and Control, 129, 571-583. https://doi. org/10.1115/1.2766721,

Nunes, M (2015). Satellite Constellation Optimization Method for Future Earth Observation Missions Using Small Satellites. Recuperado de https://www.researchgate.net/publication/272161831

Ögren, P., Fiorelli, E., Leonard, N. E., \& Member, S. (2004). Cooperative Control of Mobile Sensor Networks : Adaptive Gradient Climbing in a Distributed Environment, 49(8), 1292-1302.

Olfati-saber, B. R., Fax, J. A., \& Murray, R. M. (2007). Consensus and Cooperation in Networked Multi-Agent Systems, 95(1), 215233.

Olfati-saber, R., \& Murray, R. M. (2004). Consensus Problems in Networks of Agents With Switching Topology and Time-Delays, 49(9), 1520-1533.

Olfati-saber, R., \& Shamma, J. S. (2005). Consensus Filters for Sensor Networks and, (0), 6698-6703.

Ortega, F. (2006). Sistemas Multiagente y Fútbol de robots : Estado del Arte, 1-7. Retrieved from http://citeseerx.ist.psu.edu/ viewdoc/similar?doi=10.1.1.83.5889\&type $=c c$

Padron, A. M., Nebylov, A. \& Knyazhsky, A. (2017). Verification of the Precise Orbital Holding of Small Satellite Formation for Remote Control of Robots on a Planet Surface, 360-363.

Poghosyan, A., \& Golkar, A. (2016). Progress in Aerospace Sciences CubeSat evolution: Analyzing CubeSat capabilities for conducting science missions. Progress in Aerospace Sciences, (September), 1-25. https://doi.org/10.1016/j.paerosci.2016.11.002

Poveda G, O. S. (2016). Integración de satélites en el desarrollo de operaciones militares aéreas en Colombia según su órbita.

Radhakrishnan, R., Edmonson, W. W., Afghah, F., Rodriguez-osorio, R. M., Pinto, F. \& Burleigh, S. C. (2016). Survey of Inter-Satellite Communication for Small Satellite Systems: Physical Layer to Network Layer View.

Ren, W. (2006). Consensus Based Formation Control Strategies for Multi-vehicle Systems. American Control Conference Minneapolis, 4237-4242

Ren, W. \& Beard, R. W. (2004). Decentralized Scheme for Spacecra$\mathrm{ft}$ Formation Flying via the Virtual Structure Approach, 27(1), 73-82.

Ren, W., Beard, R. W., Atkins, E. M. \& Theory, A. G. (2005). A Survey of Consensus Problems in Multi-agent Coordination, 1859-1864.

Ren, W., Chao, H., Member, S., Bourgeous, W. \& Member, S. (2008). Experimental Validation of Consensus Algorithms for Multivehicle Cooperative Control, 16(4), 745-752.

Richard, M. (2009). Cooperative control of distributed autonomous systems with applications to wireless sensor networks. 
Rouff, C. (2000). Process for Introducing Agent Technology into Space Missions. IEEE Aerospace Conference Proceedings, 2743-2750. DOI: 10.1109/AERO.2001.931295, Recuperado de: https://ieeexplore.ieee.org/document/931295/

Ryan, A., Zennaro, M., Howell, A., Sengupta, R. \& Hedrick, J. K. (2004). An overview of emerging results in cooperative UAV control. Decision and Control, 2004. CDC. 43rd IEEE Conference On, 1, 602-607 Vol.1. https://doi.org/10.1109/CDC.2004.1428700

Saaj, C. M., Bandyopadhyay, S. \& Bandyopadhyay, B. (2010). Robust Control And Path Planning Algorithms For Small Satellite Formation Flying Missions. IAC-09-B4., 1-7. Recuperado de https://pdfs.semanticscholar.org/6d71/290b5ffde8e9d326d bd6499ae9a7cbf709d4.pdf

Sadeghi, S. \& Emami, M. R. (2017). ScienceDirect Multi-spacecraft studies of the auroral acceleration region: From cluster to nanosatellites. Advances in Space Research, 59(5), 1173-1188. Doi: https://doi.org/10.1016/j.asr.2016.11.037

Scharnagl, J., Scharnagl, J., Schilling, K., Schilling, K., Scharnagl, J. \& Schilling, K. (2016). ScienceDirect Hardware-in-theLoop Hardware-in-the-Loop Hardware-in-the-Loop Mobile Based on on Mobile Mobile Robot Platforms. IFAC-PapersOnLine, 49(30), 65-70. Doi: https://doi.org/10.1016/j.ifacol.2016.11.127

Schilling, K. (2017). Perspectives for miniaturized, distributed, networked cooperating systems for space exploration. Robotics and Autonomous Systems, 90, 118-124. Doi: https://doi. org/10.1016/j.robot.2016.10.007

Sedwick, R. J., Supervisor, T., Miller, D. W. \& Velde, W. E. Vander. (2001). Development and Analysis of a High Fidelity Linearized $J 2$ Model for Satellite Formation Flying.

Shao, X., Song, M., Wang, J., Zhang, D. \& Chen, J. (2017). Satellite formation keeping using differential lift and drag under $\mathrm{J} 2$ perturbation. Doi: https://doi.org/10.1108/AEAT-06-2015-0168

Sirigineedi, G., Tsourdos, A., White, B. A. \& Zbikowski, R. (2011). Kripke modelling and verification of temporal specifications of a multiple UAV system, 31-52. Doi: https://doi.org/10.1007/ s10472-011-9270-x

Skinnemoen, H. (2014). UAV \& Satellite Communications. IEEE, Conference on Aerospace Electronics and Remote Sensing Technology (ICARES), 12-19.

Sorensen, T. (junio, 2014). Cooperative Control of Multiple Small Satellites using the Comprehensive Open-architecture Space Mission Operations System Cooperative Control Of Multiple Small Open-Architecture Space Mission Operations.

Sun, Y. (2012). Average consensus in networks of dynamic agents with uncertain topologies and time-varying delays. Journal of the Franklin Institute, 349(3), 1061-1073. Doi: https://doi. org/10.1016/j.jfranklin.2011.12.007

Sundararaman, B., Buy, U. \& Kshemkalyani, A. D. (2005). Clock synchronization for wireless sensor networks : a survey, 3, 281323. Doi: https://doi.org/10.1016/j.adhoc.2005.01.002
Taylor, P., Wang, Q., Gao, H., Alsaadi, F. \& Hayat, T. (octubre, 2014). Systems Science \& Control Engineering: An Open An overview of consensus problems in constrained multi-agent coordination, 37-41. Doi: https://doi.org/10.1080/21642583 .2014 .897658

Truszkowski, W., Rash, J., Rouff, C. \& Hinchey, M. (2004). Some autonomic properties of two legacy multi-agent systems - LOGOS and ACT. Proceedings - 11th IEEE International Conference and Workshop on the Engineering of Computer-Based Systems, ECBS 2004, 490-498. Doi: https://doi.org/10.1109/ ECBS.2004.1316738

Tsarev, A. (2013). Smart Solutions: Multi-Agent Technology for Real-Time Enterprise Resource Management. IEEE/ACIS 12th International Conference on Computer and Information Science (ICIS), 1-6. Doi: 10.1109/ICIS.2013.6607827. Recuperado de https://ieeexplore.ieee.org/document/6607827/

Villaplana, E. (2008). Gormas: guías para el desarrollo de sistemas multiagente abiertos basados en organizaciones. Tesis Doctorado en informatica Universidad Politécnica de Valencia.

Wang, B., Wang, J., Zhang, B., S. \& Li, X. (2016). Global Cooperative Control Framework for Multiagent Systems Subject to Actuator Saturation With Industrial Applications. IEEE Transactions on Systems, Man, and Cybernetics: Systems. 1-14. Doi: 10.1109/ TSMC.2016.2573584

Wang, C., Li, J., Jing, N., Wang, J., \& Chen, H. (2011). A distributed cooperative dynamic task planning algorithm for multiple satellites based on multi-agent hybrid learning. Chinese Journal of Aeronautics, 24(4), 493-505. Doi: https://doi.org/10.1016/ S1000-9361(11)60057-5

Wang, P. (septiembre, 1996). Coordination and control of multiple microspacecraft moving in formation.

Wawrzaszek, R. \& Banaszkiewicz, M. (2007). Control and reconfiguration of satellite formations by electromagnetic forces. Journal of Telecommunications and Information Technology. 1, 54-58. Recuperado de http://yadda.icm.edu.pl/baztech/ element/bwmeta1.element.baztech-article-BAT8-0005-0012

Wei Ren, Randal W. Beard, \& E. M. A. (abril, 2007). Information Consensus in Multivehicle Cooperative Control. IEEE Control Systems Magazine, 71-82.

Weidow, D., Bristow, J. \& Weidow, D. A. (1999). NASA/DoD University Nano-Satellites for Distributed Spacecraft Control.

Xiang, C. A. O. \& Daqi, Z. H. U. (julio, 2013). A Survey of cooperative hunting control algorithms for multi-AUV systems. Conferencia presentada en Proceedings of the 32nd Chinese Control Conference, 5791-5795. Recuperado de https://ieeexplore. ieee.org/document/6640452/

Xu, Y., Fitz-Coy, N., Lind, R. \& Tatsch, A. (enero, 2007). $\mu$ Control for Satellites Formation Flying. Journal of Aerospace Engineering, 20(1). Doi: https://doi.org/10.1061/(ASCE)08931321(2007)20:1(10) 
Yeh, H., Sparks, A. \& Force, A. (junio, 2000). Geometry and Control of Satellite Formations. Conferencia presentada en Proceedings of the 2000 American Control Conference. ACC (IEEE Cat. No.00CH36334) Doi: 10.1109/ACC.2000.878926, 384-388. Recuperado de https://ieeexplore.ieee.org/document/878926/

Zampieri, S. (2008). Trends in Networked Control Systems. IFAC Proceedings Volumes (Vol. 41). IFAC. Doi: https://doi. org/10.3182/20080706-5-KR-1001.00486

Zenick, R. G. \& Kohlhepp, K. (2001). GPS Micro Navigation and Communication System for Clusters of Micro and Nanosatellites. Conferencia presentada en 2001 IEEE Aerospace Conference Proceedings (Cat. No.01TH8542), doi: 10.1109/ AERO.2001.931212. Recuperado de https://ieeexplore.ieee. org/document/931212/

Zetocha, P., Self, L., Wainwright, R. \& Burns, R., Brito, M. \& Surka, D. (2000). Commanding and controlling satellite clusters. IEEE Intelligent Systems, 15(6), 8-13. doi:10.1109/5254.895850. Recuperado de https://www.computer.org/csdl/mags/ ex/2000/06/x6008-abs.html
Zhang, H. \& Gurfil, P. (2015). Acta Astronautica Satellite cluster flight using on-off cyclic control \$. Acta Astronautica, 106, 1-12. Doi: https://doi.org/10.1016/j.actaastro.2014.10.004

Zhang, H. \& Gurfil, P. (2016). Cooperative Control of Multiple Satellites via Consensus. Conferencia presentada en 2016 24th Mediterranean Conference on Control and Automation (MED), 1102-1107. Dio: 10.1109/MED.2016.7536011. Recuperado de https://ieeexplore.ieee.org/document/7536011/

Zhu, A. \& Yang, S. X. (2010). A Survey on Intelligent Interaction and Cooperative Control of Multi-robot Systems. Conferencia presentada en IEEE ICCA 2010. 1812-1817. Doi: 10.1109/ ICCA.2010.5524132. Recuperado de https://ieeexplore.ieee. org/abstract/document/5524132/

Zhu, J., Yang, Q., Huang, W. \& Lu, R. (2015). A formal model of sateIlite communication system network control protocol based on generalized stochastic Petri nets. 2015 IEEE International Conference on Computer and Communications (ICCC), 340346. Doi://doi.org/10.1109/CompComm.2015.7387593 